\title{
The influence of soils on heterotrophic respiration exerts a strong control on net ecosystem productivity in seasonally dry Amazonian forests
}

\author{
J. R. Melton, R. K. Shrestha, and V. K. Arora \\ Canadian Centre for Climate Modelling and Analysis, Environment Canada, Victoria, BC, V8W 2Y2, Canada \\ Correspondence to: J. R. Melton (joe.melton.sci@gmail.com)
}

Received: 10 July 2014 - Published in Biogeosciences Discuss.: 21 August 2014

Revised: 6 January 2015 - Accepted: 21 January 2015 - Published: 24 February 2015

\begin{abstract}
Net ecosystem productivity of carbon (NEP) in seasonally dry forests of the Amazon varies greatly between sites with similar precipitation patterns. Correctly modeling the NEP seasonality with terrestrial ecosystem models has proven difficult. Previous modelling studies have mostly advocated for incorporating processes that act to reduce water stress on gross primary productivity (GPP) during the dry season, such as deep soils and roots, plant-mediated hydraulic redistribution of soil moisture, and increased dry season leaf litter generation which reduces leaf age and thus increases photosynthetic capacity. Recent observations, however, indicate that seasonality in heterotrophic respiration also contributes to the observed seasonal cycle of NEP. Here, we use the dynamic vegetation model CLASS-CTEM (Canadian Land Surface Scheme-Canadian Terrestrial Ecosystem Model) - without deep soils or roots, hydraulic redistribution of soil moisture, or increased dry season litter generation - at two Large-Scale Biosphere-Atmosphere Experiment (LBA) sites (Tapajós km 83 and Jarú Reserve). These LBA sites exhibit opposite seasonal NEP cycles despite reasonably similar meteorological conditions. Our simulations are able to reproduce the observed NEP seasonality at both sites. Simulated GPP, heterotrophic respiration, latent and sensible heat fluxes, litter fall rate, soil moisture and temperature, and basic vegetation state are also compared with available observation-based estimates which provide confidence that overall the model behaves realistically at the two sites. Our results indicate that representing the effect of soil moisture on heterotrophic respiration in terms of soil matric potential and constraining heterotrophic respiration when absolute soil matric potential is both low (wetter soils) and high
\end{abstract}

(drier soils), with optimum conditions in between, allows to correctly simulate NEP seasonality.

\section{Introduction}

The Amazonian region is a major component of the global terrestrial carbon cycle. Amazonian old-growth forests contain about $120 \mathrm{PgC}$ in their woody biomass (Malhi et al., 2006). The annually varying uptake and release of carbon in the region acts a powerful lever on the global carbon cycle (Bousquet et al., 2000). There has been significant interest in the region's susceptibility to release large amounts of carbon in response to recent droughts and future climate change primarily the possibility of persistent drought (Malhi et al., 2009b; Cox et al., 2013; Fu et al., 2013; Gatti et al., 2014; Zeri et al., 2014). While the northwestern Amazon experiences high rainfall year-round, areas of the centraleastern and southern edge have a dry season lasting up to 5 months (Sombroek, 2001). These seasonally dry locations are suggested to be models for the future of the Amazon's predominant wet forests (Saleska et al., 2003).

The Large-Scale Biosphere-Atmosphere Experiment (LBA) in the Amazon installed flux towers at several sites within these seasonally dry regions. Their eddy covariance measurements, which are used to estimate the net ecosystem productivity (NEP) of carbon, and energy fluxes between the land surface and the atmosphere, have served to test and improve our understanding of tropical terrestrial ecosystem processes. 
Several terrestrial ecosystem models have been evaluated against observations of NEP from LBA sites including, amongst others, CLM (Lee et al., 2005), SiB3 (Baker et al., 2008), LPJml (Poulter et al., 2009), and ISAM (ElMasri et al., 2013), along with 17 others in a modelintercomparison project (de Gonçalves et al., 2013, von Randow et al., 2013). Replicating the seasonality of NEP observations at these sites has, however, proven challenging. For example, Saleska et al. (2003) compared NEP estimates for the LBA Tapajós National Forest sites with simulated values from the TEM and IBIS models. The observation-based data showed carbon gain by the land surface in the dry season and loss in the wet; the opposite of which was simulated by the models. Accurately simulating the amplitude and timing of the NEP seasonal cycle at similar field sites continues to be challenging (see, e.g. Baker et al., 2008, 2013, von Randow et al., 2013). Attempts have been made to correct the unrealistic simulated NEP seasonal cycle by representing processes deemed important to capture the regional carbon dynamics including (i) deep roots to allow access to deep soil water reserves (Baker et al., 2008, 2013; Poulter et al., 2009), (ii) hydraulic redistribution (HR) of soil moisture via plant roots (Lee et al., 2005), (iii) deeper soil profiles (Baker et al., 2013), and (iv) adjusting the response of heterotrophic respiration to soil moisture (Baker et al., 2008). The inclusion of these processes is, of course, not based on the modeler's fancy but on field observations and measurements such as those of Nepstad et al. (1994; deep roots), Oliveira et al. (2005; HR), and Bruno et al. (2006; soil moisture in a deep soil column).

More recent studies attempt to include yet another physical process in their modelling framework that imposes a decrease in leaf age during the dry season in tropical forests. In models with this parameterization, decreasing leaf age increases photosynthetic capacity and thus primary productivity during the dry season. Kim et al. (2012), who use the ED2 model, increase leaf litter generation during the dry season by parameterizing leaf litter as a function of incoming solar radiation. The basis of this is that the dry season in seasonally dry tropical forests experiences more radiation due to lower cloud cover. For the ORCHIDEE model, De Weirdt et al. (2012) parameterize increased litter generation by continually generating leaf litter when the leaf area index (LAI) reaches 6 . The daily leaf litter amount equals the amount of carbon allocated to leaves, so that the LAI stays at 6 but the leaf age decreases. Both these parameterizations attempt to generate peak leaf litter production during the early dry season in line with observations (Goulden et al., 2004).

Thus, previous modeling studies of seasonally dry forests have placed a greater emphasis on increasing primary productivity during the dry season either through the influence of soil moisture or through decreasing leaf age. Relatively less emphasis has been placed on the response of heterotrophic respiration which is equally important in determining NEP seasonality.
Recent observation-based estimates from Rowland et al. (2014) at a site in French Guiana indicate that heterotrophic respiration reduces during the dry season in these seasonally dry Amazonian tropical forests. Rowland et al. (2014) attempt to model the seasonal cycle of gross primary productivity (GPP) and heterotrophic respiration by calibrating their model's parameters separately for the dry and wet seasons at their site. Their calibrated heterotrophic respiration parameters for the litter, coarse woody debris, and soil organic matter pools of their model were about $35 \%$ lower during the dry compared to the wet season.

Here, we test the hypothesis that the seasonality in heterotrophic respiration exerts a strong control on the seasonality of NEP in seasonally dry tropical forests. We aim to evaluate the CLASS-CTEM (Canadian Land Surface SchemeCanadian Terrestrial Ecosystem Model) dynamic vegetation model which does not include deep roots, root-mediated hydraulic redistribution of soil moisture particularly deep soils or representation of decreased leaf age during the dry season. We assess if appropriately representing the influence of soil texture and depth - through soil moisture - on seasonal patterns of GPP and, more importantly, on heterotrophic respiration yields realistic simulated NEP seasonality at two LBA sites which experience relatively similar climatic conditions yet exhibit opposite NEP seasonality.

We use the CLASS-CTEM dynamic vegetation model which is briefly described in Sect. 2. The response of heterotrophic respiration to soil moisture in this model is based on a parameterization that uses soil matric potential and which assumes that heterotrophic respiration is constrained when soil is both dry and wet, with optimum values in between. We do not calibrate the parameters of the model used, nor do the parameters values depend on the season. We also test an alternative parameterization in which the response of heterotrophic respiration to soil moisture is modelled using a simple linear relationship (similar to Rohr et al., 2013) that progressively constrains heterotrophic respiration as soil moisture reduces from field capacity to wilting point. Both parameterizations are described in Sect. 2. Results are provided in Sect. 3, which show reasonable comparison of simulated GPP, latent and sensible heat fluxes, litter fall rate, and soil moisture and temperature with available observationbased estimates and suggest that the model overall behaves realistically at the two chosen sites. The simple parameterization for modelling the response of heterotrophic respiration to soil moisture is, however, unable to realistically model the observed NEP seasonality. The results provide insight as to which features of our standard parameterization, which models the heterotrophic respiration response to soil moisture, contribute to improved simulated seasonality of NEP. Finally conclusions are provided in Sect. 4. Our results reinforce the importance of accurate site-specific soil information and support our hypothesis that the response of heterotrophic respiration to seasonal reduction in soil moisture exerts a strong 
control on the seasonality of carbon fluxes between the atmosphere and land surface in seasonally dry tropical forests.

\section{Methods}

\subsection{The CLASS-CTEM model}

The CLASS-CTEM model used here is formed by coupling the Canadian Land Surface Scheme (CLASS v. 3.6; Verseghy, 2012) and the Canadian Terrestrial Ecosystem Model (CTEM v. 1.2; Melton and Arora, 2014). Earlier versions of these models are currently incorporated into the Canadian Centre for Climate Modelling and Analysis Earth System Model (CanESM2; Arora et al., 2011). When coupled together both models simulate fluxes of energy, water and $\mathrm{CO}_{2}$ at the land-atmosphere boundary. In the simulations presented here, CLASS-CTEM is driven with observation-based meteorological forcing including: precipitation, specific humidity, air pressure, wind speed, air temperature, and downwelling longwave and shortwave radiation.

CLASS calculates the energy and water balance of the vegetation canopy, soil, and snow components with a $30 \mathrm{~min}$ time step. It simulates the temperature and liquid and frozen moisture contents for up to three soil layers that are 0.10 , 0.25 , and up to $3.75 \mathrm{~m}$ deep. The maximum soil depth is thus $4.1 \mathrm{~m}$. Energy and water balance calculations are performed for up to four plant functional types (PFTs) (needleleaf trees, broadleaf trees, crops, and grasses) using prescribed structural attributes for each PFT (including rooting depth, plant height which determines the surface roughness length, canopy mass, and leaf area index (LAI)). When coupled to CTEM, as done in this study, these variables are dynamically simulated by CTEM and passed to CLASS.

CTEM simulates terrestrial ecosystem processes for nine PFTs that are directly related to the four CLASS PFTs. Needleleaf trees are separated into evergreen and deciduous; broadleaf trees into evergreen, cold deciduous, and drought/dry deciduous; and crops and grasses are separated into $\mathrm{C}_{3}$ and $\mathrm{C}_{4}$. Photosynthesis and canopy conductance in CTEM are simulated at the same time step as CLASS (i.e. $30 \mathrm{~min}$ ). Other terrestrial ecosystem processes are simulated at a daily time step, including autotrophic and heterotrophic respiration (Arora, 2003); allocation; phenology and turnover (Arora and Boer, 2005); and conversion of biomass to structural attributes (including dynamic roots; Arora and Boer, 2003). The model consists of three living vegetation components (leaves, stem, and root) and two dead carbon pools (litter and soil organic matter).

The NEP of carbon, also termed the net ecosystem exchange (NEE), in CTEM is modeled as the difference between GPP and the autotrophic $\left(R_{\mathrm{a}}\right)$ and heterotrophic $\left(R_{\mathrm{h}}\right)$ respiratory fluxes as

$$
\begin{aligned}
& \mathrm{NEP}=\left(\mathrm{GPP}-R_{\mathrm{a}}\right)-R_{\mathrm{h}}, \\
& \mathrm{NEP}=\mathrm{NPP}-R_{\mathrm{h}},
\end{aligned}
$$

where NPP is net primary productivity, obtained by subtracting $R_{\mathrm{a}}$ from GPP. Positive values of NEP indicate that land gains carbon from the atmosphere. Autotrophic respiration is calculated as the sum of growth and maintenance respiration for the plant tissues.

\subsection{Heterotrophic respiration and its response to soil moisture}

Heterotrophic respiration in CLASS-CTEM is modelled following Arora (2003) with some minor differences. Heterotrophic respiration $\left(R_{\mathrm{h}}\right)$ is the sum of respiration from the model's litter $\left(R_{\mathrm{h}_{\mathrm{L}}}\right)$ and soil carbon pools $\left(R_{\mathrm{h}_{\mathrm{S}}}\right)$ :

$R_{\mathrm{h}}=R_{\mathrm{h}_{\mathrm{L}}}+R_{\mathrm{h}_{\mathrm{S}}}$.

Respiration in these pools is influenced by the amount of carbon $\left(\mathrm{C}_{\mathrm{L}}\right.$ and $\left.\mathrm{C}_{\mathrm{S}} ; \mathrm{kg} \mathrm{Cm}^{-2}\right)$, and a specified PFT-dependent respiration rate at $15^{\circ} \mathrm{C}\left(\varsigma_{\mathrm{L}}\right.$ and $\varsigma_{\mathrm{S}} ; \mathrm{kgC}(\mathrm{kgC})^{-1}$ day $\left.^{-1}\right)$ that is modulated by a temperature-dependent $Q_{10}$ function, $f\left(Q_{10}\right)$, and a soil matric potential dependence, $(f(\psi))$, that models the effect of soil moisture as

$$
\begin{aligned}
& R_{\mathrm{H}_{\mathrm{L}}}=\varsigma_{\mathrm{L}} \mathrm{C}_{\mathrm{L}} f\left(Q_{10_{\mathrm{L}}}\right) f_{\mathrm{L}}(\psi), \\
& R_{\mathrm{H}_{\mathrm{S}}}=\varsigma_{\mathrm{S}} \mathrm{C}_{\mathrm{S}} f\left(Q_{10_{\mathrm{S}}}\right) f_{\mathrm{S}}(\psi) .
\end{aligned}
$$

The values of $\varsigma_{\mathrm{S}}$ and $\varsigma_{\mathrm{L}}$ for broadleaved evergreen trees, the PFT specified at the two LBA sites studied here, are 0.0208 and $0.6339 \mathrm{kgC}(\mathrm{kgC})^{-1} \mathrm{day}^{-1}$, respectively. The temperature-dependent $Q_{10}$ function, $f\left(Q_{10}\right)$, is given by $Q_{10}^{\frac{T-15}{10}}$, where $T\left({ }^{\circ} \mathrm{C}\right)$ is the litter $\left(T_{\mathrm{L}}\right)$ or soil temperature $\left(T_{\mathrm{S}}\right)$. The litter pool contains litter from the stem, leaf, and root components. The litter temperature is then a weighted average of the soil temperature of the top layer (as a surrogate for a litter layer temperature) and the mean soil temperature in the rooting zone. The soil carbon in each layer is not explicitly tracked but assumed to adopt an exponential distribution (similar to roots; see Fig. 4 of Jobbágy and Jackson, 2000). $T_{\mathrm{S}}$ is the temperature of the soil carbon pool calculated from the temperature of the individual soil layers weighted by the fraction of soil carbon in each layer. The litter and soil moisture respiration parameters are meant to yield average turnover times of around 1-2 years for litter and 10-40 years for soil carbon, depending on the climate and consistent with observation-based estimates from litter bag experiments (Zhang et al., 2008) and similar experiments for soil carbon. In addition, the model parameters are fine tuned on a global scale to account for differences in litter chemistry of different PFTs (e.g. litter from needleleaf trees generally has lower decomposability compared to the litter from broadleaf trees) and to obtain reasonable global 
scale geographic distribution of litter and soil carbon when the model is driven with observation-based climate.

CTEM v. 1.2 (Melton and Arora, 2014) used here implements a slightly different $Q_{10}$ parameterization than CTEM v. 1.0 (Arora, 2003). The $f\left(Q_{10}\right)$ function uses a temperature-dependent $Q_{10}$ through a unique formulation in the form of a hyperbolic tan function:

$Q_{10}=1.44+0.56 \tanh [0.075(46.0-T)]$.

This formulation is a tradeoff between the common temperature-independent $Q_{10}$ of many terrestrial ecosystem models (e.g. Cox, 2001) and the temperature-dependent $Q_{10}$ of Kirschbaum (1995). The use of a constant $Q_{10}$ implies that respiration rate will increase indefinitely as temperature increases. Conversely, the Kirschbaum (1995) formulation yields a continuously increasing $Q_{10}$ as temperature decreases, leading to unreasonably high litter and soil carbon stores at high latitudes in CLASS-CTEM. The CLASSCTEM formulation Eq. (6) gives a $Q_{10}$ value of around 2 below $20^{\circ} \mathrm{C}$, while for higher temperatures the respiration rate does not continuously increase.

The response of heterotrophic respiration to soil moisture is modelled using the soil moisture scalar $(f(\psi))$ which uses soil matric potential $(\psi)$ instead of soil moisture $(\theta)$. Typically, soil matric potential is at, or near, zero when the soil is saturated becoming increasingly negative as the soil dries. Davidson et al. (2000) and Orchard and Cook (1983) show that soil respiration rates are linearly correlated with the logarithm of soil matric potential. Soil matric potential, of course, depends on soil moisture $(\theta)$ but is also a function of soil texture. The soil matric potential $(\psi(\theta))$ is defined following Clapp and Hornberger (1978) as

$\psi(\theta)=\psi_{\text {sat }}\left(\frac{\theta}{\theta_{\text {sat }}}\right)^{-B}$,

where $\Psi_{\text {sat }}$ is the saturated matric potential, $\theta_{\text {sat }}$ is the saturated soil moisture content (equivalently the soil porosity) and $B$ is the empirical Clapp-Hornberger parameter. $\Psi_{\text {sat }}$, $\theta_{\text {sat }}$, and $B$ are calculated as a function of percentage sand $\left(P_{\text {sand }}\right)$ and clay $\left(P_{\text {clay }}\right)$ in the soil, following Verseghy (1991, 2012), as

$\psi_{\text {sat }}=\frac{10^{-0.0131 P_{\text {sand }}+1.88}}{100}$,
$\theta_{\text {sat }}=\frac{-0.126 P_{\text {sand }}+48.9}{100}$,
$B=0.159 P_{\text {clay }}+2.91$.

In principle, other functional forms such as those of Brooks and Corey (1966) and Van Genuchten (1980) may also be used.

The primary premise of soil moisture control on heterotrophic respiration $\left(f_{\mathrm{S}, \mathrm{L}}(\psi)\right)$ is that heterotrophic respiration is constrained both when the soils are dry and when they are wet, and optimum conditions lie in between. In very dry soils (absolute soil matric potential $>100 \mathrm{MPa}$ ), the soil moisture scalar for both litter and soil carbon is small, limiting microbial respiration. As soils wet and absolute matric potential decreases, heterotrophic respiration increases to a peak when the absolute matric potential is between 0.04 and $0.06 \mathrm{MPa}$. Griffin (1981) suggests that the microbial activity is optimal at an absolute soil matric potential of $0.05 \mathrm{MPa}$ and decreases as the soil becomes waterlogged near $0.00 \mathrm{MPa}$ or too dry near $1.5 \mathrm{MPa}$. Decreasing the absolute matric potential further to the saturated matric potential reduces the soil moisture scalar reflecting impeded oxygen supply to microbes. The litter microbial respiration is influenced by the matric potential of the top soil layer except it is unimpeded by low absolute matric potentials as it is assumed to be continually exposed to air. While soil matric potential values are usually negative, the absolute value is used here to ensure logarithmic mathematics can be performed. Higher absolute values of soil matric potential are associated with drier soils. As such, litter and soil carbon differ only for $0.04>\Psi \geq \Psi_{\text {sat }}$, where litter respiration is assumed to not be constrained by high soil moisture content. The resulting soil moisture scalars for heterotrophic respiration from litter and soil carbon pools are shown in Fig. 1a and vary with matric potential as

$0.04>\Psi \geq \Psi_{\text {sat }}$ :

$f_{\mathrm{S}}(\psi)=1-0.5 \frac{\log (0.04)-\log \psi}{\log (0.04)-\log \psi_{\mathrm{sat}}}$,

$f_{\mathrm{L}}(\psi)=1$,

$0.06 \geq \Psi \geq 0.04$ :

$f_{\mathrm{S}, \mathrm{L}}(\psi)=1$,

$100.0 \geq \Psi>0.06:$

$f_{\mathrm{S}, \mathrm{L}}(\psi)=1-0.8 \frac{\log \psi-\log (0.06)}{\log (100)-\log (0.06),}$

$\Psi>100.0$ :

$f_{\mathrm{S}, \mathrm{L}}(\psi)=0.2$

\section{An alternative simple linear parameterization}

We also use an alternative simple linear parameterization for modelling heterotrophic respiration's response to soil moisture (similar to Rohr et al., 2013). In this simple parameterization, the soil moisture scalar for heterotrophic respiration is expressed as a function of soil moisture. As soil moisture $(\theta)$ decreases from field capacity $\left(\theta_{\mathrm{f}}\right)$ to wilting point $\left(\theta_{\mathrm{w}}\right)$, the scalar reduces from one to zero, and this reduces heterotrophic respiration as soils dry. The field capacity soil moisture corresponds to hydraulic conductivity of $0.10 \mathrm{~mm} \mathrm{day}^{-1}$ and wilting point soil moisture corresponds to a matric potential of $150 \mathrm{~m}$ water head equivalent (i.e 

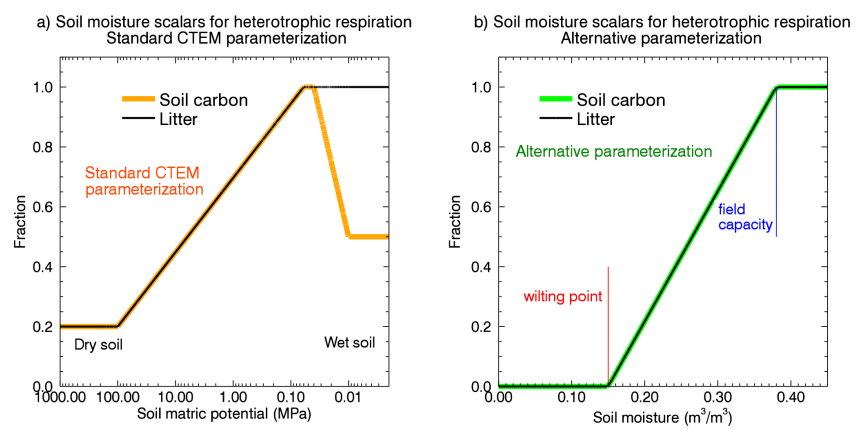

Figure 1. Soil moisture scalars for modelling the effect of soil moisture on heterotrophic respiration from litter and soil carbon pools. (a) The standard parameterization used in CLASS-CTEM. (b) The alternative parameterization as discussed in Sect. 2.2.

1.47 MPa). This simple soil moisture scalar is thus expressed as

$$
\begin{aligned}
& f_{\mathrm{S}, \mathrm{L}}(\theta)=1 ; \quad \theta>\theta_{\mathrm{f}}, \\
& f_{\mathrm{S}, \mathrm{L}}(\theta)=\frac{\theta-\theta_{\mathrm{w}}}{\theta_{\mathrm{f}}-\theta_{\mathrm{w}}} ; \quad \theta_{\mathrm{w}}<\theta<\theta_{\mathrm{f}}, \\
& f_{\mathrm{S}, \mathrm{L}}(\theta)=0 ; \quad \theta<\theta_{\mathrm{w}},
\end{aligned}
$$

and shown in Fig. $1 b$.

Finally, a weighted value of the soil moisture scalar for respiration from the soil carbon pool $\left(f_{\mathrm{S}}(\psi)\right.$ or $\left.f_{\mathrm{S}}(\theta)\right)$ is found based on fraction of soil carbon in each soil layer that is assumed to follow an exponential distribution.

\subsection{Description of LBA sites}

CLASS-CTEM simulations were performed for two LBA sites in the Amazon: (1) Tapajós National Forest near kilometer 83 of the Santarém-Cuiabá highway (hereafter K83, $54^{\circ} 56^{\prime} \mathrm{W}, 3^{\circ} 3^{\prime} \mathrm{S}$ ) and (2) Jarú Reserve (hereafter RJA, $61^{\circ} 56^{\prime} \mathrm{W}, 10^{\circ} 5^{\prime} \mathrm{S}$ ) (Fig. 2a). Both sites have been extensively documented (Goulden et al., 2004; da Rocha et al., 2004, 2009; Miller et al., 2004; Keller et al., 2004; Restrepo-Coupe et al., 2013). Field data for these sites cover the periods: 2001-2003 for K83 and 2000-2002 for RJA. These sites were chosen due to their opposing seasonal pattern of NEP; both sites have a distinct dry season, but the land surface at RJA loses carbon to the atmosphere during the dry season while $\mathrm{K} 83$ does so during the wet season.

We view K83 and RJA as having "functionally" similar climates with regards to their timing, intensity, and duration of the dry season. While these two sites do differ somewhat in their climates, they share enough commonalities in climate to suggest that they have similar NEP seasonal dynamics, rather than the out-of-phase behaviour that is observed and discussed in the Introduction.

K83 is a moist, closed canopy tropical evergreen forest with a 5-month dry season starting in July (defined by $<100 \mathrm{~mm}$ of precipitation in a month; Fig. 2b). Tempera- tures vary little year-round with a mean surface air temperature of $26^{\circ} \mathrm{C}$ (Fig. 2c) and mean annual precipitation over the study period of ca. $1650 \mathrm{~mm}$. The site was selectively logged starting in 2001 (Miller et al., 2007), coincident with the time period investigated. This selective logging at K83 is reported to not significantly influence the energy and carbon fluxes when compared to a nearby undisturbed site (Tapajós National Forest site $67 \mathrm{~km}$; Miller et al., 2007, 2011). Soil depth at $\mathrm{K} 83$ is $>12 \mathrm{~m}$ (Oliveira et al., 2005). The soil is a claytexture Oxisol with patches of sandy-loam textured Ultisol (Silver et al., 2000; Keller et al., 2005).

RJA is a tropical wet and dry, closed canopy evergreen forest. RJA has a higher mean annual precipitation (ca. $2350 \mathrm{~mm}$ ) than $\mathrm{K} 83$, but a drier and shorter dry season (ca. 4 months) starting in May (Fig. 2b). Surface air temperature is generally slightly higher at K83 (Fig. 2c) with both showing little seasonal variation in surface temperature (ca. 2$3^{\circ} \mathrm{C}$ ). RJA has higher mean annual downwelling solar radiation than K83 (Fig. 2d) while both K83 and RJA have small peaks in solar radiation corresponding to the reduced cloud cover of the dry season. Soil depth at RJA is reported to be $1 \mathrm{~m}$ (Restrepo-Coupe et al., 2013) and between 0.2 and $4 \mathrm{~m}$ (Andreae et al., 2002). The RJA soils have a high sand content (Andreae et al., 2002; de Gonçalves et al., 2013).

Most observation-based estimates we use here for model evaluation are ground-based observations at the RJA and K83 field sites (see Table 1 and Sect. 3), however we also compare to remotely sensed GPP provided via the MODIS dataset. We used the improved MOD17A2 data set from the Numerical Terradynamic Simulation Group (NTSG), which contains an 8-day summation of GPP. These data are freely available from the NTSG (http://www.ntsg.umt.edu) and are corrected for cloud contamination and spatial smoothing of meteorological forcing data. Data gaps in the 8-day MODIS fractional photsynthetically active radiation (FPAR)/LAI that are labeled as cloud-contaminations are filled with linearly interpolated data based on reliable FPAR/LAI. More details can be found in Zhao et al. (2005) and Heinsch et al. (2003).

\subsection{CLASS-CTEM simulations}

Because the CLASS and CTEM models are designed for application at large spatial scales in an Earth system model (ESM), they are not tuned for any specific location but are expected to behave reasonably realistically at all locations. This is the general expectation from similar land surface parameterization schemes and terrestrial ecosystem models implemented in other ESMs. Melton and Arora (2014) show that the CLASS-CTEM modelling framework reproduces reasonable spatial patterns of gross and net primary productivity, heterotrophic respiration, and terrestrial vegetation and soil carbon pools at the global scale when driven with observation-based climate forcing. Site-specific testing of models, such as the one presented in this study, allows one to further evaluate if model parameterizations of physi- 

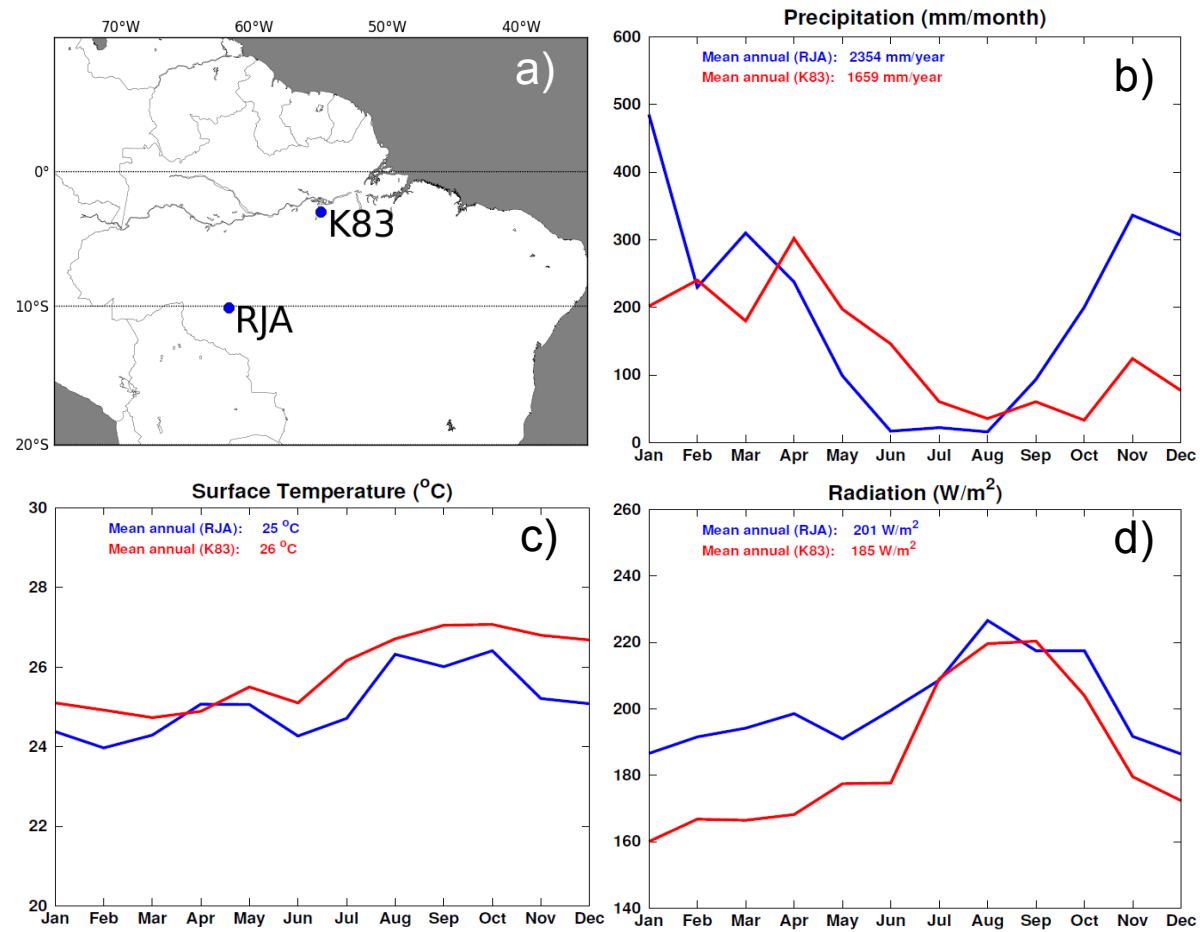

Figure 2. (a) Location of the K83 (Tapajós River National Forest site $83 \mathrm{~km}$ ) and RJA (Jarú Reserve) sites. Observed climate used for forcing CLASS-CTEM over the 2001-2003 period for K83 and the 2000-2002 period for RJA including mean monthly (b) precipitation, (c) surface air temperature, and (d) downward flux of solar radiation.

Table 1. Simulated primary carbon pools and vegetation state from CLASS-CTEM compared to site-level observations for the Tapajós River National Forest site (K83) and Jarú Reserve (RJA). LAI is leaf area index.

\begin{tabular}{|c|c|c|c|}
\hline Variable & Site & CLASS-CTEM & Observed \\
\hline \multirow[t]{2}{*}{$\operatorname{LAI}\left(\mathrm{m}^{2} \mathrm{~m}^{-2}\right)$} & K83 & 5.0 & 4.9 (Doughty and Goulden, 2008) \\
\hline & RJA & 6.1 & 5.5 (Andreae et al., 2002) \\
\hline \multirow[t]{2}{*}{ Total vegetation biomass $\left(\mathrm{kg} \mathrm{C} \mathrm{m}^{-2}\right)$} & K83 & 14.5 & $18.6 \pm 10.3^{\mathrm{a}}($ Keller et al., 2001) \\
\hline & RJA & 17.3 & - \\
\hline \multirow[t]{2}{*}{ Aboveground vegetation biomass $\left(\mathrm{kg} \mathrm{Cm}^{-2}\right)$} & K83 & 12.5 & $\begin{array}{l}\text { 13.2 } 2^{\mathrm{b}} \pm 6.8 \text { (Miller et al., 2004; Keller et al., 2001), } \\
15.6 \text { (Saleska et al., 2003) }\end{array}$ \\
\hline & RJA & 14.9 & - \\
\hline \multirow[t]{2}{*}{ Belowground vegetation biomass $\left(\mathrm{kgCm}^{-2}\right)$} & K83 & 2.0 & $\begin{array}{l}3.2 \pm 2.3 \text { (Keller et al., } 2001) \\
3.6 \text { (Silver et al., } 2000)\end{array}$ \\
\hline & RJA & 2.4 & - \\
\hline \multirow[t]{2}{*}{ Soil carbon $\left(\mathrm{kgCm}^{-2}\right)$} & K83 & 13.0 & $10.1 \pm 0.4-14.2 \pm 0.7^{\mathrm{c}}$ (de Carvalho et al., 2003) \\
\hline & RJA & 11.5 & - \\
\hline \multirow[t]{2}{*}{ Litter $\left(\mathrm{kgCm}^{-2}\right)$} & K83 & 0.8 & $0.3^{\mathrm{d}}$ (Hirsch et al., 2004) \\
\hline & RJA & 0.6 & - \\
\hline
\end{tabular}

a Value includes trees, vines, and epiphytes.

${ }^{\mathrm{b}}$ Calculated from Table 4 of Keller et al. (2001). Value does not include vines and epiphytes. Converted from organic matter to carbon assuming $50 \%$ carbon by mass in dry organic matter.

${ }^{c}$ Measurements of carbon in the mineral-organic matter down to a depth of $2.1 \mathrm{~m}$. The lower value is from the more common clay oxisols. The CLASS-CTEM model was run assuming a soil texture of the clay oxisols following de Gonçalves et al. (2013).

${ }^{\mathrm{d}}$ Litterfall estimate includes only leaves. Value is from A.M.S. Figueira (unpublished data) as reported in Hirsch et al. (2004). 
cal and biogeochemical processes hold at point scales. This site-specific testing, of models designed for implementation at large spatial scales, is arguably a more stringent test of their abilities.

For the two LBA sites investigated here, we used the "off-the-shelf" version of the CLASS-CTEM model (as reported in Melton and Arora, 2014), i.e. model parameters were not changed or tuned to improve model performance. Such model parameters include maximum photosynthesis rates, base respiration rates for autotrophic and heterotrophic respiration, and allocation parameters that determine allocation of carbon from leaves to stem and root components, amongst several others parameters, for CTEM. As described in Sect. 2.2, we tested the model performance using two different parameterizations of heterotrophic respiration, with both model versions independently spun-up to equilibrium as described below.

Simulations were performed for the broadleaf evergreen tree PFT with $100 \%$ fractional cover. The soil depth was set to the full soil column at K83 (4.1 m) and $1 \mathrm{~m}$ at RJA. Both sites have three soil layers, but the thickness of the third soil layer for RJA is $0.65 \mathrm{~m}$ rather than $3.75 \mathrm{~m}$ as at K83. Soil textural information was adopted following Table 2 in de Gonçalves et al. (2013). The specification of soil texture is done through the percentage of sand and clay in the soil. At RJA, the percentages of sand in the first, second, and third soil layers are specified at 80,70 , and $60 \%$, and percentage of clay at 10,20 , and $30 \%$, respectively. At K83, the percentages of sand in the first, second, and third soil layers are specified at 18,20 , and $15 \%$, and percent clay at 80,75 , and $80 \%$, respectively. In the full Earth system modelling framework, specification of geophysical fields of soil depth and soil texture is based on global data sets such as that of Zobler (1986), itself based on the FAO soil data. Other soil information besides texture and depth, e.g. $\mathrm{pH}$ and cation exchange capacity, are not presently considered.

All simulations were forced with gap-filled meteorological data from the LBA Data Model Intercomparison Project (de Gonçalves et al., 2013). The data are available at an hourly time step but were changed to half-hourly resolution via linear interpolation, except for solar radiation and precipitation for which an hourly value was assumed to stay the same over 2 half-hourly intervals. Atmospheric $\mathrm{CO}_{2}$ concentration was set at a constant $375.0 \mathrm{ppm}$.

Since our focus is on the seasonality of simulated NEP, the model pools were spun up by repeatedly using the 3 years of observed climate for each site until they reached equilibrium and the annually averaged NEP was close to zero. Land use change and disturbance (fire) modules were not used in these simulations.

\section{Results}

\subsection{Basic vegetation state}

The basic vegetation state simulated by CLASS-CTEM compares well to the available observation-based estimates (Table 1). CLASS-CTEM simulates reasonable LAIs with a slight overestimate at RJA but matching observations at K83. The total vegetation biomass simulated by CLASSCTEM at K83 is somewhat lower than observed. Our underestimation could be due to a lower carbon use efficiency (CUE; ratio of NPP / GPP) simulated at this site than in reality. CUE is affected by several factors including stand age and the ratio of leaf mass to total mass (DeLucia et al., 2007). Our K83 CUE estimate (ca. 0.31) is in line with measurements by Malhi et al. (2009a) for LBA sites with shorter dry seasons (Manaus K34: $0.34 \pm 0.10$ and Caxiuanã: $0.32 \pm 0.07$ ), but lower than a nearby site (Tapajós $67 \mathrm{~K}$ : $0.49 \pm 0.16$ ) with similar dry season length to K83. Our underestimate likely reflects our use of a single PFT, without site-level calibration of model parameters, to characterize the diversity of tropical broadleaf evergreen trees. As a result, the total biomass simulated is somewhat lower than observed for both the aboveground and belowground biomass pools. The modeled soil carbon pool compares well with estimates, while the litter pool is larger than observed as the simulated litter pool includes contributions from not only leaves, but stems and roots as well. Overall, CLASS-CTEM reasonably simulates the forest structure at K83, although there are many fewer data available for model evaluation at RJA.

\subsection{Carbon fluxes}

The NEP estimates derived from eddy covariance measurements at K83 and RJA are shown in Fig. 3a along with the simulated CLASS-CTEM values. The annual mean is subtracted from the monthly observation-based values so that they are directly comparable to simulated values with a net zero annual NEP. Simulated NEP at both sites shows good agreement with observation-based estimates for both timing and amplitude (at $\mathrm{K} 83 R^{2}=0.81$, root mean standard error $(\mathrm{RMSE})=11.99 \mathrm{~g} \mathrm{Cm}^{-2}$ month $^{-1}$; at RJA $R^{2}=0.51$, $\mathrm{RMSE}=15.34 \mathrm{~g} \mathrm{C} \mathrm{m}^{-2}$ month $\left.^{-1}\right)$. CLASS-CTEM successfully captures carbon uptake by land at K83 and loss at RJA during the dry season. To better understand how CLASSCTEM is able to realistically capture the seasonal NEP dynamics, we look at its constituent components - GPP, NPP, $R_{\mathrm{a}}$, and $R_{\mathrm{h}}$ - as a realistic NEP estimate is dependent upon realistic seasonal cycles of GPP, $R_{\mathrm{a}}$ and $R_{\mathrm{h}}$.

The simulated GPP at RJA is shown in Fig. $3 \mathrm{~b}$ together with the MODIS estimated GPP (Zhao et al., 2005). While the simulated GPP averages about $10 \%$ higher than the MODIS estimate, they both exhibit a significant drop in GPP as the dry season progresses (of similar magnitude, ca. $22 \%$ for MODIS and ca. $24 \%$ for CLASS- 

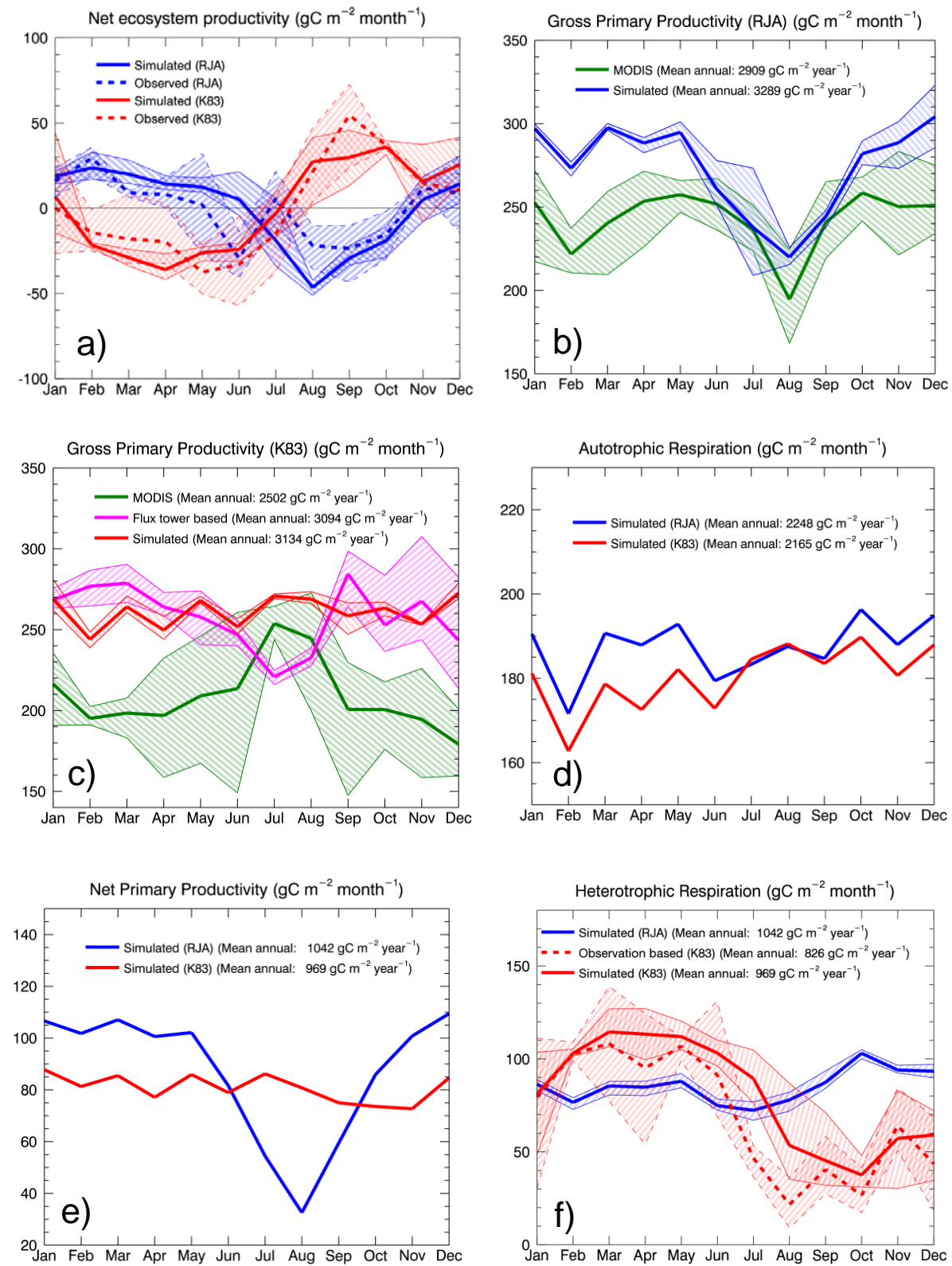

Figure 3. (a) Observed and CLASS-CTEM-simulated mean monthly NEP at RJA (Jarú Reserve) and K83 (Tapajós River National Forest site $83 \mathrm{~km}$ ). All simulations used the standard CLASS-CTEM heterotrophic respiration parameterization (see Sect. 2.2). Positive NEP values indicate carbon uptake by the land surface from the atmosphere; negative values the opposite. All values are presented as anomalies to allow easier comparison of the seasonal patterns. (b) RJA mean monthly GPP as simulated by CLASS-CTEM and estimated by MODIS (Zhao et al., 2005). (c) K83 mean monthly GPP from MODIS, CLASS-CTEM, and a flux-tower based estimate from Miller et al. (2009). CLASSCTEM-simulated mean monthly (d) autotrophic respiration, (e) net primary productivity, and (f) heterotrophic respiration for RJA and K83. Panel (f) also shows an observation-based estimate for heterotrophic respiration at the K83 site that is derived by subtracting a constant annual mean simulated autotrophic respiration of $180 \mathrm{~g} \mathrm{C} \mathrm{m}^{-2} \mathrm{month}^{-1}$ from an observation-based estimate of ecosystem respiration (Miller et al., 2009) as explained in Sect. 3.2. Shaded regions in panels (a) through (c) denote the range over a given month of the 3 years of climate data used. 
CTEM, and bottoming out in August), $R^{2}=0.50, \mathrm{RMSE}=$ $36.6 \mathrm{~g} \mathrm{C} \mathrm{m}^{-2}$ month $^{-1}$. At K83, CLASS-CTEM simulates no seasonal drop in GPP (Fig. 3c). The flux-tower-based GPP estimate from Miller et al. (2009) shows a small decrease, with the lowest values in July while the MODIS estimate increases over the same period (Fig. 3c). It is not readily apparent which of the two estimates is correct. The behavior of CLASS-CTEM-simulated GPP falls between the two observation-based estimates (CTEM-MODIS $R^{2}=0.14$, RMSE $=55.96 \mathrm{~g} \mathrm{Cm}^{-2}$ month $^{-1}$ and CTEMFlux tower $R^{2}=0.26$, RMSE $=24.62 \mathrm{~g} \mathrm{Cm}^{-2}$ month $^{-1}$ ). Both K83 and RJA experience increases in downwelling solar radiation during the dry season due to less cloud cover (Fig. 2d); however, the influence on NEP seasonality is relatively weak due to the already high insolation levels (not shown). This lack of light limitation in these regions has also been reported by a recent remote sensing study (Morton et al., 2014). The difference in the GPP seasonal cycle at $\mathrm{K} 83$ vs. RJA is interesting. The dry season decrease in simulated GPP at RJA is due to both the shallow soil column and the sandy soil texture. In our simulations, the soil column extends to a maximum of $4.1 \mathrm{~m}$ (as is the case for K83), while the soil column at RJA was set to $1 \mathrm{~m}$ (Sects. 2.2 and 2.3). The shallow soil column, together with a sandy soil texture, causes the RJA vegetation to experience more dry-season water stress than at K83. The deep soil column and lower hydraulic conductivity (associated with higher clay content) at K83 gives lower drainage rates leading to higher soil moisture levels and plant available water during the dry season (as shown later in Fig. 7) compared to RJA.

How is CLASS-CTEM able to accurately simulate GPP during the dry season without explicit simulation of deep roots, HR, or particularly deep soils? The answer appears to be due to a combination of factors, the most important of which is the site specification of the geophysical fields of soil depth and soil texture. The soil depth at RJA is shallow. Simulations with the standard CLASS-CTEM soil depth for this grid cell (4.1 m; based upon values in Zobler, 1986) result in little water stress (and thereby little GPP suppression), while incorporating the observed shallow soil depth greatly improved the simulation result. Rooting depth in CLASSCTEM also influenced the K83 GPP as CLASS-CTEM has a dynamic root distribution (Arora and Boer, 2003). While not an explicit representation of deep roots, regions with extended dry seasons cause the plants to allocate more carbon to roots, allowing access to moisture by roots in the model's lowest soil layer. The water loss from transpiration in CLASS-CTEM is proportional to fraction of roots present in each soil layer. The same fraction of roots in each soil layer is also used to calculate water stress on photosynthesis. Shallower soil depth implies, that the fraction of roots in deeper soil layers is reduced, which increases water stress on photosynthesis and also reduces transpiration during the dry season.
The CLASS-CTEM-simulated autotrophic respiration values for RJA and K83 show relatively little variation throughout the year with similar mean annual values of around $2.2 \mathrm{~kg} \mathrm{C} \mathrm{m}^{-2}$ year $^{-1}$ (Fig. 3d). RJA has a slightly higher $R_{\mathrm{a}}$ value than $\mathrm{K} 83$, reflecting its higher simulated total biomass (Table 1). The constancy of $R_{\mathrm{a}}$ indicates the seasonal cycle of NPP at these sites (Fig. 3e) is primarily driven by changes in GPP (Fig. 3b and c). This constancy in autotrophic respiration is consistent with observation-based estimates of Rowland et al. (2014) from a seasonally dry Amazonian forest in French Guiana.

The simulated heterotrophic respiration $\left(R_{\mathrm{h}}\right)$ seasonal cycles at RJA and K83 are, like GPP, very different between the sites (Fig. 3f). Simulated $R_{\mathrm{h}}$ at $\mathrm{K} 83$ shows a large seasonal cycle (amplitude of ca. $80 \mathrm{~g} \mathrm{Cm}^{-2}$ month $^{-1}$ ) with a peak in the wet season and a low at the end of the dry season. RJA, conversely, has a small seasonal cycle (amplitude of $<30 \mathrm{~g} \mathrm{C} \mathrm{m}^{-2}$ month $^{-1}$ ), but a similar annual total to $\mathrm{K} 83\left(1042 \mathrm{~g} \mathrm{Cm}^{-2} \mathrm{yr}^{-1}\right.$ and $969 \mathrm{~g} \mathrm{Cm}^{-2} \mathrm{yr}^{-1}$ at RJA and K83, respectively) and a peak in October as the precipitation starts increasing after the dry season ends. The simulated difference in seasonal cycle of $R_{\mathrm{h}}$ between the sites corresponds to how soil moisture and texture influence $R_{\mathrm{h}}$. Figure $3 \mathrm{f}$ also compares the CTEMsimulated seasonal cycle of heterotrophic respiration at K83 with a quasi-observation-based estimate $\left(R^{2}=0.81\right.$, $\mathrm{RMSE}=17.82 \mathrm{~g} \mathrm{C} \mathrm{m}^{-2} \mathrm{month}^{-1}$ ). Miller et al. (2009) provide an observation-based estimate of ecosystem respiration $\left(R_{\mathrm{a}}+R_{\mathrm{h}}\right)$ for the K83 site. There are no similar observations available for RJA. The quasi-observation-based estimate of heterotrophic respiration is obtained by assuming that the autotrophic respiration is constant throughout the year (equal to the annual mean simulated by CLASSCTEM, $180 \mathrm{~g} \mathrm{C} \mathrm{m}^{-2}$ month $^{-1}$ ) and by subtracting it from the observation-based ecosystem respiration. In the absence of separate observation-based estimates of $R_{\mathrm{a}}$ and $R_{\mathrm{h}}$, this is a reasonable assumption since both the air temperature and simulated autotrophic respiration show very little seasonality. A similar assumption is made by Rowland et al. (2014), who estimate root respiration by assuming that it is constant and that the seasonal changes in soil respiration are caused by heterotrophic processes. Derived in this way, the seasonality and amplitude of the annual cycle of the quasi-observationbased estimate of heterotrophic respiration compares well with the values simulated by CLASS-CTEM.

The seasonality in simulated heterotrophic respiration at K83 and RJA is primarily the result of the seasonality in soil matric potential at these sites since air temperature (Fig. 2c) shows relatively small seasonality. Simulated daily average soil moisture scalars for heterotrophic respiration from litter and soil carbon pools at the two sites are shown in Fig. 4 and explain the seasonality of simulated heterotrophic respiration at the two sites. These soil moisture scalars are based on Eqs. 9-13. RJA soils have a high sand content while K83 soils have a high clay content (Sect. 2.3). For the same soil 


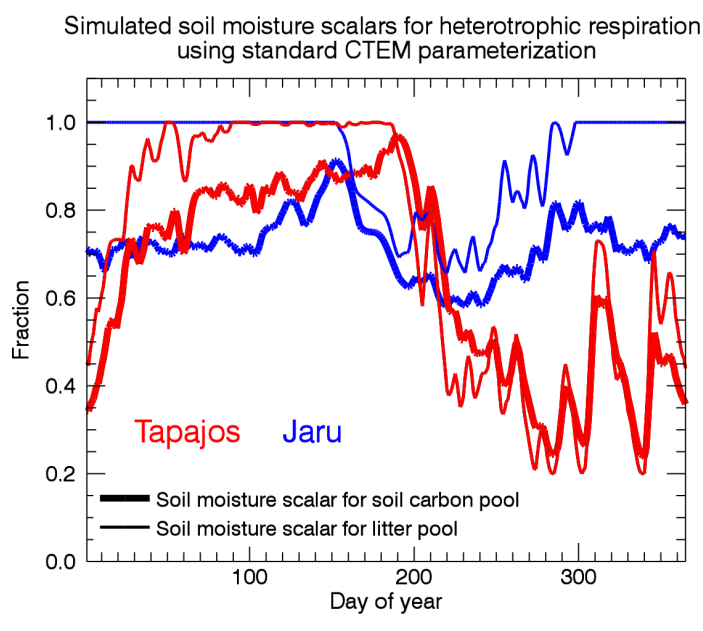

Figure 4. Daily mean simulated heterotrophic respiration soil moisture scalar for K83 (Tapajós $83 \mathrm{~km}$ ) and RJA (Jarú Reserve) for litter $\left(f_{\mathrm{L}}(\psi)\right)$ and soil carbon $\left(f_{\mathrm{S}}(\psi)\right)$ averaged across 3 years $(2001-$ 2003 for K83 and 2000-2002 for RJA).

moisture, the absolute matric potential is higher for clay-rich soils compared to sandy ones. The influence of these differences in soil texture on the $R_{\mathrm{h}}$ soil moisture scalar for litter and soil carbon is visible in Fig. 4. The high sand content at RJA results in a relatively stable soil matric potential, and the resulting stable soil moisture scalar for $R_{\mathrm{h}}$, throughout the year. This relatively steady matric potential, along with stable temperatures at RJA (Fig. 2c), gives low seasonal variability in $R_{\mathrm{h}}$ (Fig. 3f). Conversely, during the rainy season, when soils are wet, K83's absolute matric potential is lower than at RJA; while as the dry season progresses, its absolute matric potential becomes higher due to clay tightly binding the steadily decreasing soil water which limits $R_{\mathrm{h}}$. Combined with realistic simulated GPP seasonality, CLASSCTEM yields seasonality of NEP that compares well with observation-based NEP at both locations.

\subsection{Energy fluxes}

Figure 5 shows the simulated seasonality of energy fluxes and Bowen ratio at the two sites compared to available eddy-covariance-based estimates. Both simulated net radiation (Fig. 5a), and simulated and eddy-covariance-based estimates of latent (Fig. 5b) and sensible (Fig. 5c) heat fluxes, as well as the Bowen ratio (Fig. 5d), do not show any significant seasonality. CTEM-simulated net radiation compares well to observations at both $\mathrm{K} 83\left(R^{2}=\right.$ $\left.0.67, \mathrm{RMSE}=9.78 \mathrm{~W} \mathrm{~m}^{-2} \mathrm{month}^{-1}\right)$ and RJA $\left(R^{2}=0.89\right.$, RMSE $\left.=3.97 \mathrm{~W} \mathrm{~m}^{-2} \mathrm{month}^{-1}\right)$. Simulated latent heat flux is higher than observations at both sites. Simulated sensible heat flux at $\mathrm{K} 83$ has a poor correlation with observations, while at RJA, simulated sensible heat flux compares reasonably well with observations $\left(R^{2}=0.48\right.$, RMSE $=$ $8.03 \mathrm{~W} \mathrm{~m}^{-2}$ month $\left.^{-1}\right)$. The simulated Bowen ratio compares reasonably with the eddy-covariance-based estimate at RJA $\left(R^{2}=0.32, \mathrm{RMSE}=0.054\right)$ but poorly at $\mathrm{K} 83\left(R^{2}=0.12\right.$, RMSE $=0.200$ ), with lower simulated values than observations. We note that the observations from K83 have energy balance closure but those from RJA do not. This implies that CTEM does not partition the sensible and latent heat fluxes correctly at $\mathrm{K} 83$, which is a deficiency in the model. However, the simulated seasonality of latent heat fluxes $\left(\mathrm{K} 83 R^{2}=0.59, \mathrm{RMSE}=20.02 \mathrm{~W} \mathrm{~m}^{-2}\right.$ month $^{-1}$; RJA $R^{2}=0.34$, RMSE $=25.50 \mathrm{~W} \mathrm{~m}^{-2}$ month $^{-1}$ ) compares well with the eddy-covariance-based estimates. Both the simulated and eddy-covariance-based latent heat fluxes peak in same months of October and August/September at the RJA and K83 sites, respectively. The simulated sensible heat fluxes, however, peak a month (August) earlier at the RJA site than the eddy-covariance-based estimate (September).

\subsection{Litter fall rate and litter and soil carbon pools}

Figure 6 shows the seasonality in litter fall rate, and the litter and soil carbon pools. In Fig. 6a, the simulated litter fall rate at the K83 site is compared with the observation-based estimate. The observation-based estimate includes leaf litter, fallen wood, and flowers and reproductive organs (http://daac.ornl.gov/LBA/guides/CD04_Leaf_Litter. html, Goulden et al., 2004) but covers only 1 year (2002). The simulated litter fall rate includes litter from the leaves and the stem components of the model and shows the model average and range over the 3 years (2001-2003) from which climate data are used repeatedly. Observation-based litter fall peaks during the beginning of dry season while the simulated litter fall, which primarily responds to soil moisture, and peaks in October when the soil is driest (Fig. $7 \mathrm{~d} ; R^{2}=0.11$, $\mathrm{RMSE}=27.85 \mathrm{~g} \mathrm{C} \mathrm{m}^{-2}$ month $\left.^{-1}\right)$. The simulated annual litter fall rate is also about $30 \%$ lower than the observationbased estimate. Since there is only 1 year of observed litter fall data, it is uncertain how representative this year is, but it is assumed here to be reasonably typical. This discrepancy in the total amount and the seasonality of litter fall rate simulated by terrestrial ecosystem models has been noted by De Weirdt et al. (2012) and Kim et al. (2012), both of which attempt to parameterize increased litter fall during the dry season using different methods. To influence the timing of litter fall, Kim et al. (2012) make leaf litter fall rate a function of 10-day averaged radiation in the Ecosystem Demography (ED2) model and test the parameterization at the Tapajós $67 \mathrm{~km}$ site. Since seasonally dry tropical forests experience higher radiation during the drier, relatively cloud-less season, the parameterization results in increased leaf litter generation during the dry season. As photosynthetic capacity in ED2 is inversely proportional to leaf longevity, increased dry season litter generation leads to a reduction in mean leaf age and thereby increased photosynthetic capacity. De Weirdt et al. (2012) use an entirely different approach to generate increased leaf litter during the dry season. They use 

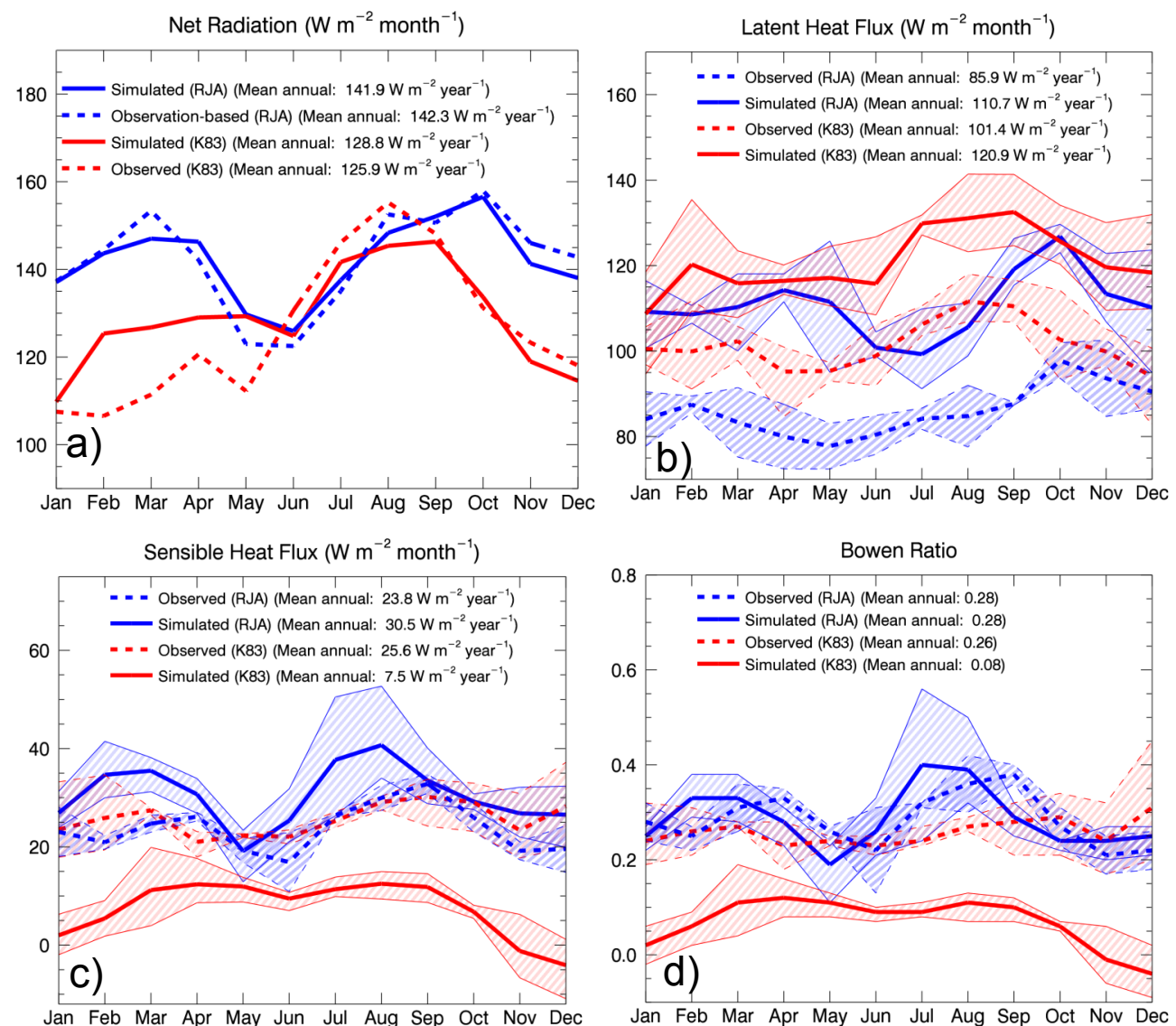

Figure 5. Simulated and eddy-covariance-based estimates of energy fluxes and the Bowen ratio at the K83 (Tapajós 83 km) and RJA (Jarú Reserve) sites. (a) Net radiation, (b) latent heat fluxes, (c) sensible heat fluxes, and (d) Bowen ratio. Shaded regions in panels (b) through (d) denote the range over a given month of the 3 years of climate data used.

the ORCHIDEE model, which is the terrestrial carbon cycle component of the Institut Pierre Simon Laplace (IPSL) ESM (Dufresne et al., 2013); therefore, similar to CTEM, sitespecific parameterizations and coefficients cannot be used. Assuming leaf turnover as a strategy for leaf renewal to increase light use, De Weirdt et al. (2012) parameterize leaf litter generation such that when LAI is greater than 6 , the carbon lost through litter generation by the oldest leaves is equal to the carbon allocated to making new leaves. The ORCHIDEE model tracks leaf age in four age classes, and maximum photosynthetic rate is a function of leaf age. Thus, similar to the ED2 model, increased leaf litter generation decreases leaf age and increases primary productivity. CTEM does not represent this process of enforced increased dry season leaf litter generation and reduced leaf age. In CTEM, leaf litter generation is based on a base leaf loss rate that increases due to drought and cold stress.

Figure $6 \mathrm{~b}$ shows the simulated litter fall rate from the leaves and the stem components of CTEM at the RJA site which peaks during August when the soil is the most dry (Fig. 7b). In Fig. 6c, the simulated litter pools at the K83 and
RJA sites show some seasonality while the simulated soil carbon pools (Fig. 6d) do not.

\subsection{Soil moisture and temperature}

The simulated soil temperature and soil moisture compares reasonably with available observation-based estimates at K83 (Fig. 7) $\left(10 \mathrm{~cm}\right.$ depth: $R^{2}=0.77, \mathrm{RMSE}=1.26^{\circ} \mathrm{C}$, $20 \mathrm{~cm}$ depth: $R^{2}=0.80$, RMSE $=1.18^{\circ} \mathrm{C}$, and $50 \mathrm{~cm}$ depth: $R^{2}=0.77$, RMSE $=1.04^{\circ} \mathrm{C}$ ), although the simulated seasonality in modelled values is higher and simulated soil moisture is lower than observed at 20 and $40 \mathrm{~cm}$ depths (Fig. $7 \mathrm{~d})\left(10 \mathrm{~cm}\right.$ depth: $R^{2}=0.87, \mathrm{RMSE}=0.05 \mathrm{~m}^{3} \mathrm{~m}^{-3}$, $20 \mathrm{~cm}$ depth: $R^{2}=0.82$, RMSE $=0.14 \mathrm{~m}^{3} \mathrm{~m}^{-3}$, and $40 \mathrm{~cm}$ depth: $R^{2}=0.88$, RMSE $=0.14 \mathrm{~m}^{3} \mathrm{~m}^{-3}$ ). Simulated soil moisture and temperature are not directly comparable to observations since observations correspond to a specific depth while the model simulated soil moisture and temperature correspond to averages over its respective three soil layers. The simulated values reported in Fig. 7 at depths corresponding to observations are obtained by assuming that the modelled 

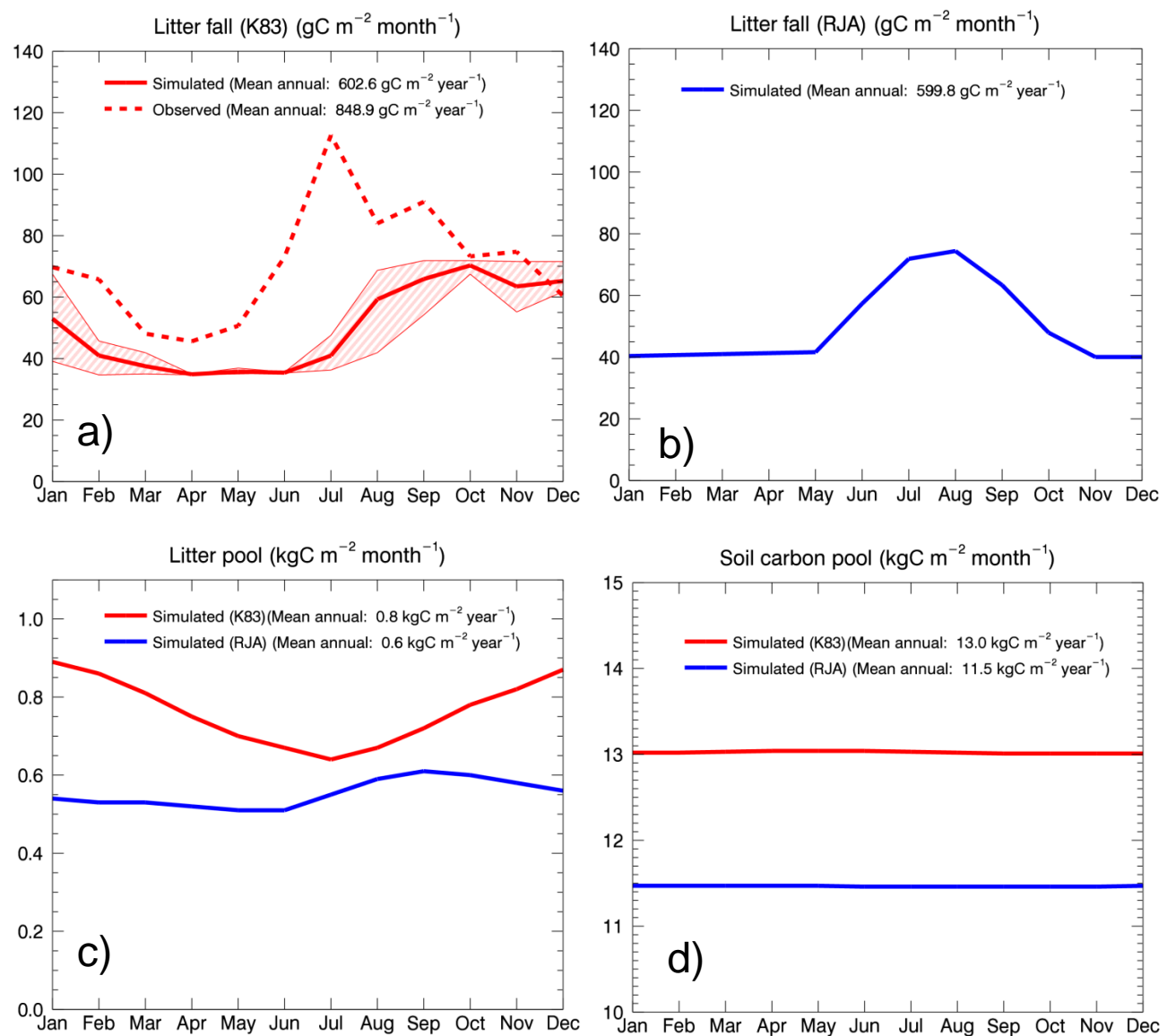

Figure 6. Comparison of simulated and observation-based litter fall rates (a and b) at K83 (Tapajós $83 \mathrm{~km}$ ) and RJA (Jarú Reserve) sites. (c) and (d) show simulated litter and soil carbon pool sizes at the two sites. The shaded region in (a) denotes the range over a given month of the 3 years of climate data used. The observation-based estimate (Goulden et al., 2004) at K83 covers only one year (2002).

soil moisture and temperature correspond to the centre of its three soils layers and linearly interpolating between them.

Land surface schemes are known to simulate different soil moisture states when driven with the same meteorological forcing; each with its own mean state and a preferred "operating range" of soil moisture (see, e.g. Dirmeyer, 2011). So the bias in simulated soil moisture at $20 \mathrm{~cm}$ and $40 \mathrm{~cm}$ is not of particular concern given that CLASS-CTEM reasonably simulates the timing of the onset of dry and wet states. Note that while the bias in mean soil moisture can be accounted for by adjusting the base heterotrophic respiration rates for litter and soil carbon, it is difficult to account for incorrect seasonality in simulated soil moisture.

\subsection{Alternative parameterization}

The results from the use of the alternative simple linear parameterization for modelling the response of heterotrophic respiration to soil moisture (Eq. 14) are shown in Fig. 8. This alternative parameterization yields an increased amplitude of the simulated seasonal cycle of heterotrophic respiration for both sites (Fig. 8a), compared to the results from the standard parameterization shown earlier (Fig. 3f). The result of this increased seasonality is that the simulated annual cycle of NEP at RJA is reversed and the amplitude of simulated seasonal NEP cycle is larger at K83 (Fig. 8b). The RMSE and $R^{2}$ values when using the alternative parameterization $\left(\mathrm{K} 83 R^{2}=0.10, \mathrm{RMSE}=35.70 \mathrm{~g} \mathrm{C} \mathrm{m}^{-2}\right.$ month $^{-1}$; RJA $R^{2}=0.20$, RMSE $=28.75 \mathrm{~g} \mathrm{Cm}^{-2}$ month $^{-1}$ ) are also poorer at both sites compared to the standard parameterization $\left(\mathrm{K} 83 R^{2}=0.81\right.$, RMSE $=11.99 \mathrm{~g} \mathrm{Cm}^{-2}$ month $^{-1}$; RJA $R^{2}=0.51$, RMSE $=15.34 \mathrm{~g} \mathrm{Cm}^{-2} \mathrm{month}^{-1}$ ). At RJA, GPP decreases during the dry season (Fig. 3b). The use of the alternate parameterization, for modelling the response of heterotrophic respiration to soil moisture decreases heterotrophic respiration during the dry season to a larger extent than the decrease in GPP, and as a result the carbon uptake by land occurs during the dry season, contrary to observations. When using the CLASS-CTEM standard parameterization, the decrease in heterotrophic respiration is much smaller than the decrease in GPP and the land loses carbon during the dry season, consistent with observations. At K83, since the simulated GPP does not exhibit any significant seasonality 
(Fig. 3c), the seasonality in NEP is the result of seasonality in heterotrophic respiration. As a result, an increased amplitude of the simulated seasonal cycle of heterotrophic respiration with the alternative parameterization gives an increased amplitude of the simulated annual cycle of NEP, which does not compare well with observation-based estimates.

\section{Discussion and conclusions}

Accurate simulation of NEP in seasonally dry Amazonian forests has proven challenging for many terrestrial ecosystem models. Earlier studies have mostly suggested including processes such as deep roots, plant-mediated hydraulic redistribution of soil moisture, and deep soils that help increase dry season GPP. Baker et al. (2008) also adjusted the response of heterotrophic respiration to soil moisture in their model to correctly simulate the seasonality of carbon fluxes. More recent studies of Kim et al. (2012) and De Weirdt et al. (2012) include yet another physical process that aims to reduce leaf age, and thus increase primary production, by generating more leaf litter during the dry season as the observations suggest. Both these studies use different parameterizations to achieve this effect with varying success. In particular, the parameterization used by De Weirdt et al. (2012) improves and increases the simulated GPP at the Guyaflux site during the dry season (their Fig. 8a), but the increase in dry season GPP at the Tapajós km 67 site makes the comparison with observations worse than their standard model version (their Fig. 8b). Additionally, Poulter et al. (2009) used a phenology parameterization based on radiation (similar to Kim et al., 2012) and found, at least in the LPJml model, that the influence of seasonality in LAI was unimportant compared to deep roots and soil in contributing to NEP seasonality.

Recent observation-based estimates from Rowland et al. (2014) for a seasonally dry tropical forest site in French Guiana show that heterotrophic respiration reduces during the dry season, while autotrophic respiration does not. Since air temperature does not exhibit any significant seasonality in these forests, the seasonality of NEP is primarily controlled by the seasonality in precipitation and soil moisture. As a result then, the simulated response of both GPP and heterotrophic respiration to soil moisture must be correctly captured to realistically model NEP in seasonally dry tropical forests.

\subsection{Simulation of NEP}

We use observed net ecosystem productivity fluxes from two sites in the LBA network (K83 and RJA) to test the hypothesis that seasonality in heterotrophic respiration exerts a strong control on the seasonality of NEP by using the CLASS-CTEM model that is designed for implementation at large spatial scales in the Canadian Earth system model. These sites have similar climates but yield opposing pat- terns of seasonal NEP. CLASS-CTEM is used "off-the-shelf" without the inclusion of deep roots and soils, without hydraulic redistribution of soil moisture, and without any processes that enforce decreased leaf age during the dry season.

The CLASS-CTEM model realistically simulates the timing and magnitude of the NEP seasonal cycle at both K83 and RJA as well as the relatively small seasonality in the energy fluxes at both sites. Our simulations suggest that CLASSCTEM performs well due to two main factors: site-specific geophysical information about soil texture and depth, and an appropriate heterotrophic respiration response to soil moisture expressed in terms of soil matric potential. These results support our hypothesis that heterotrophic respiration exerts a strong control on the seasonality of NEP in seasonally dry tropical forests. The defining characteristic of these two LBA sites, as expressed in our simulations, is their differing soils, given they have similar vegetation and climate.

\subsection{Heterotrophic respiration response to soil moisture}

While the decrease in heterotrophic respiration during the dry season is essential to simulating the correct seasonality in NEP, how much reduction in heterotrophic respiration occurs is also important. The simple alternative linear parameterization that progressively reduces heterotrophic respiration as soils get drier is unable to correctly reproduce the seasonality of NEP at both sites. There are two main differences between the standard parameterization used in CTEM and the simple alternative parameterization that we have used to model the response of heterotrophic respiration to soil moisture. First, the response of heterotrophic respiration to soil moisture is parameterized in terms of soil matric potential in the standard CLASS-CTEM parameterization while it is parameterized in terms of soil moisture itself in the simple alternative parameterization. Second, the standard CLASSCTEM parameterization assumes that soil moisture conditions for heterotrophic respiration are optimum when the soil is neither too dry nor too wet, while the alternative parameterization assumes that heterotrophic respiration is not constrained at high soil moisture, and it reduces progressively to zero as soils get drier. Both of these differences contribute to improve simulated NEP seasonality at the two sites in the standard CLASS-CTEM parameterization. Additional simulations performed with a variant of the alternative parameterization (not shown) suggest that the factor most influencing these two sites is that heterotrophic respiration does not shut down completely when the soil moisture is below the wilting point.

\subsection{Litter fall}

In the end, a realistic simulation of NEP at both sites is the result of the overall reasonable performance of the various components of the model as confirmed by comparing simulated basic vegetation state, GPP, heterotrophic respiration, 

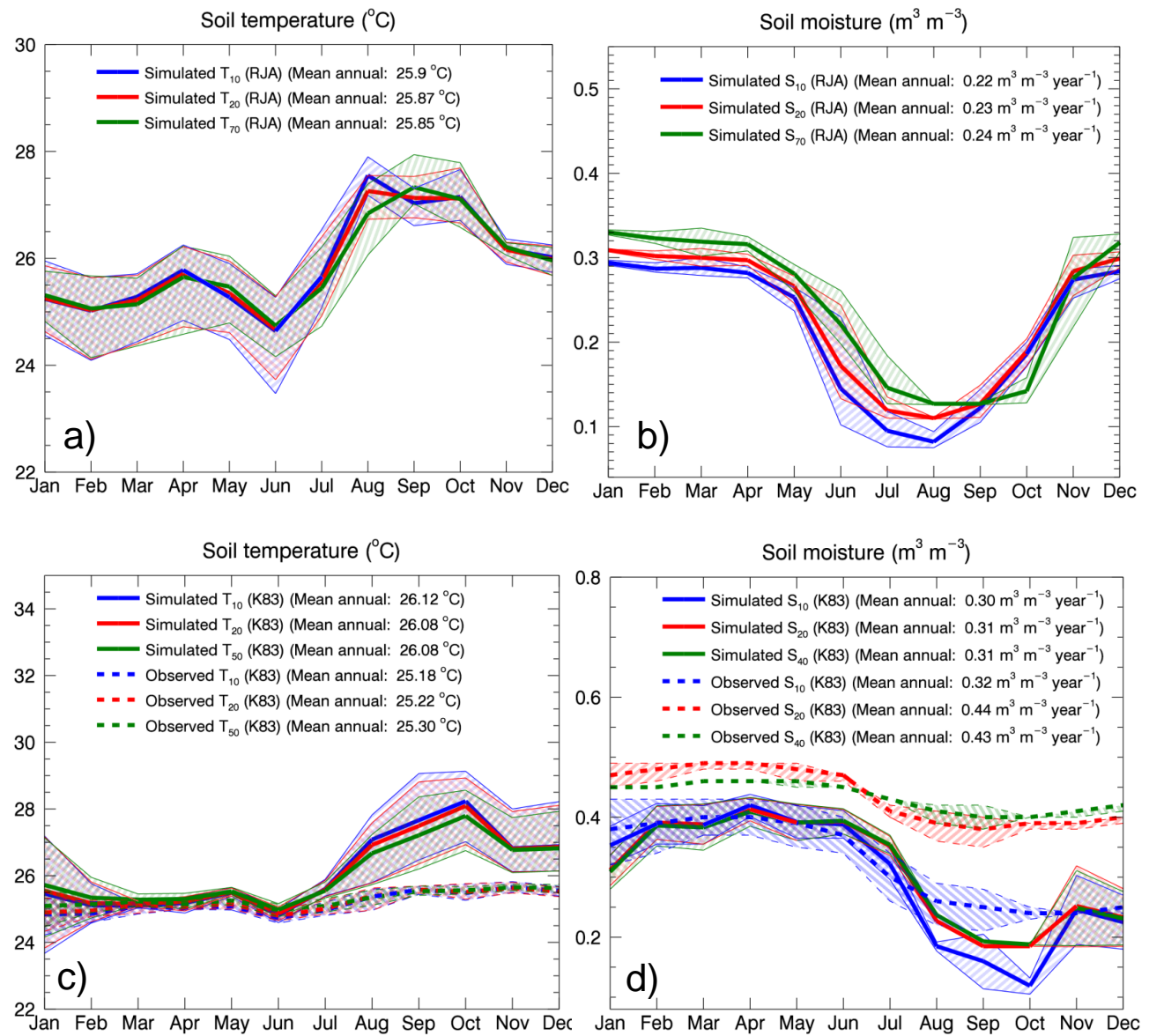

Figure 7. Simulated soil temperature (a, c) and soil moisture (b, d) at the RJA (Jarú Reserve) and K83 (Tapajós 83 km) sites. Observationbased soil temperature and moisture at K83 are also shown in (c) and (d) for soil depths given in centimetres.
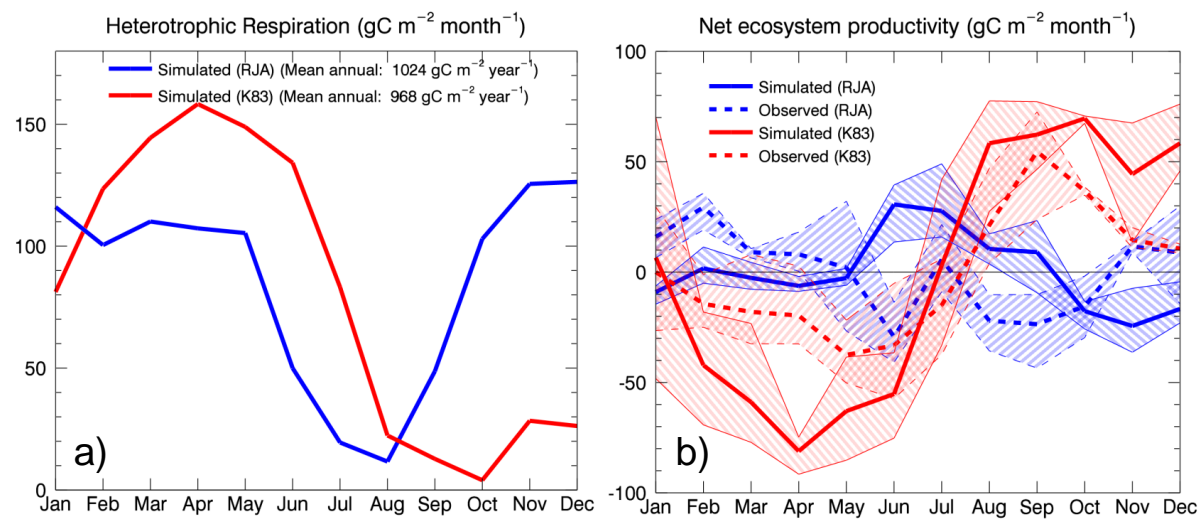

Figure 8. (a) Simulated heterotrophic respiration at the RJA and K83 sites when using the alternative parameterization to model the response of heterotrophic respiration to soil moisture (Sect. 2.2). (b) The resulting simulated NEP at the two sites is compared with observation-based estimates. The shaded range in (b) corresponds to the range over the 3 years.

latent and sensible heat fluxes, net radiation, and soil moisture and temperature against available observation-based estimates. The simulated litter fall rate, however, shows some limitations. As with most terrestrial ecosystem models, the litter fall rate in CTEM is based on leaf lifespan and responds to soil moisture and temperature. The simulated litter fall rate peaks at the end of the dry season at both K83 and RJA sites in response to the driest soil moisture conditions, while ob- 
servations suggest that litter fall rates peak during the beginning of dry season, at least at the K83 site. This limitation in simulated litter fall is, however, not expected to substantially affect the seasonality of simulated heterotrophic respiration. This is confirmed by comparing Figs. 3f and 6c. The simulated heterotrophic respiration at K83 is lowest in October while the litter pool is at its lowest in July. Improved seasonality in litter fall rate would somewhat change the seasonality of the litter pool, but as long as litter is available the seasonality of heterotrophic respiration at these sites is primarily determined by the soil moisture and temperature scalars in Eq. (4). Our results then suggest that (1) it is possible to realistically simulate the opposite NEP seasonality at the two sites considered here, without including processes that aim to increase dry season GPP, (2) the response of heterotrophic respiration to soil moisture appears to play an important role in simulating the NEP seasonality, and (3) the NEP seasonality is simulated more realistically when the response of heterotrophic respiration to soil moisture includes consideration of soil matric potential and an optimum soil moisture when the soil is neither too dry nor too wet. Given the sensitivity of simulated heterotrophic respiration to soil texture and soil depth, the results indicate that these geophysical fields must be specified as realistically as possible.

\subsection{Final comments}

The results of this study are also relevant for application of the Canadian and other ESMs to study the effect of climate change on the global carbon cycle. Arora and Boer (2014), for example, investigate the effect of the climate change and increasing atmospheric $\mathrm{CO}_{2}$ on the global land carbon budget with a focus on the Amazonian region using results from the second-generation Canadian ESM (CanESM2). The evaluation of simulated atmosphere-land energy and $\mathrm{CO}_{2}$ fluxes by CLASS-CTEM against site-specific observationbased data provides excellent opportunities to assess its performance, compared to the usual evaluation exercises where the broad geographical distribution of simulated primary carbon fluxes and pools is compared with observation-based estimates (e.g. Melton and Arora, 2014). Indeed, the evaluation of models designed for implementation at large spatial scales against observation-based energy and $\mathrm{CO}_{2}$ fluxes at a point location is a more stringent test of their abilities.

Greater understanding of the Amazonian region provided by observations has been used to improve models, but at the same time models have provided new insights themselves. Models remain, however, only a representation of reality. For a given ecosystem under consideration, different models often yield different results providing, sometimes widely, different perspectives on the behavior of an ecosystem. In the end, the confluence of the modeling and observation efforts are a consensus-building exercise to determine how an ecosystem responds to biotic and abiotic drivers. The current consensus about seasonally dry tropical forests is that deep roots and soils, and hydraulic redistribution of soil moisture play an important role in the seasonality of energy and $\mathrm{CO}_{2}$ fluxes. As a result, these processes have been incorporated into models as part of attempts to correctly simulate NEP seasonality. However, any new processes incorporated into a model bring with them a raft of imperfect parameterizations and "tunable" parameters that can easily result in problems with equifinality (Tang and Zhuang, 2008), where any model response can be achieved by simply tuning parameters.

While recognized in the existing literature, the role of an appropriate heterotrophic respiration response to soil conditions has been relatively under-appreciated. This is perhaps not surprising because GPP estimates reproduced from a typical set of eddy covariance measurements are much more widely reported and reliable than the heterotrophic respiration measurements which exhibit significant spatial heterogeneity. Recent observation-based estimates from Rowland et al. (2014), however, indicate the important role of heterotrophic respiration. As NEP is the balance between heterotrophic respiration and net primary productivity, accurate simulation of heterotrophic respiration is equally vital to estimates of NEP. Together with an understanding of the response of heterotrophic respiration to seasonally varying soil moisture as seen in observation-based estimates from Rowland et al. (2014), the results provided in this study suggest that the under-appreciated role of soil moisture in controlling heterotrophic respiration deserves attention as well.

Author contributions. V. Arora initiated the study, J. Melton and V. Arora designed experiments. R. Shrestha ran simulations, performed statistics, and created figures. J. Melton and V. Arora analyzed the results and wrote the manuscript.

Acknowledgements. J. R. Melton was supported by a National Scientific and Engineering Research Council of Canada (NSERC) Visiting Postdoctoral Fellowship. R. K. Shrestha was supported by the Canadian Network for Regional Climate and Weather Processes (CNRCWP), which is funded by the Climate Change and Atmospheric Research initiative of NSERC. We thank the LBA project for making their data available, and in particular Celso Von Randow for sharing RJA NEP data. We thank Maosheng Zhao for helping us access the MODIS GPP data. All data generated by CLASS-CTEM is available from CCCma upon completion of a licensing agreement. We also thank Ian Baker and Mathew Williams for their helpful comments on the discussion version of this paper.

Edited by: M. Williams

\section{References}

Andreae, M. O., Artaxo, P., Brandão, C., Carswell, F. E., Ciccioli, P., da Costa, A. L., Culf, A. D., Esteves, J. L., Gash, J. H. C., Grace, J., Kabat, P., Lelieveld, J., Malhi, Y., Manzi, A. O., 
Meixner, F. X., Nobre, A. D., Nobre, C., Ruivo, M. d. L. P., SilvaDias, M. A., Stefani, P., Valentini, R., von Jouanne, J., and Waterloo, M. J.: Biogeochemical cycling of carbon, water, energy, trace gases, and aerosols in Amazonia: the LBA-EUSTACH experiments, J. Geophys. Res.-Atmos., 107, LBA33-1-LBA33-25, 2002.

Arora, V. K.: Simulating energy and carbon fluxes over winter wheat using coupled land surface and terrestrial ecosystem models, Agr. Forest Meteorol., 118, 21-47, 2003.

Arora, V. K. and Boer, G. J.: A representation of variable root distribution in dynamic vegetation models, Earth Interact., 7, 1-19, 2003.

Arora, V. K. and Boer, G. J.: A parameterization of leaf phenology for the terrestrial ecosystem component of climate models, Glob. Change Biol., 11, 39-59, 2005.

Arora, V. K. and Boer, G. J.: Terrestrial ecosystems response to future changes in climate and atmospheric $\mathrm{CO}_{2}$ concentration, Biogeosciences, 11, 4157-4171, doi:10.5194/bg-11-4157-2014, 2014.

Arora, V. K., Scinocca, J. F., Boer, G. J., Christian, J. R., Denman, K. L., Flato, G. M., Kharin, V. V., Lee, W. G., and Merryfield, W. J.: Carbon emission limits required to satisfy future representative concentration pathways of greenhouse gases, Geophys. Res. Lett., 38, L05805, doi:10.1029/2010GL046270, 2011.

Baker, I., Harper, A., da Rocha, H., Denning, A., Araújo, A., Borma, L., Freitas, H., Goulden, M., Manzi, A., Miller, S., Nobre, A., Restrepo-Coupe, N., Saleska, S., Stöckli, R., von Randow, C., and Wofsy, S.: Surface ecophysiological behavior across vegetation and moisture gradients in t ropical South America, Agr. Forest Meteorol., 182, 177-188, 2013.

Baker, I. T., Prihodko, L., Denning, A. S., Goulden, M., Miller, S., and da Rocha, H. R.: Seasonal drought stress in the Amazon: reconciling models and observations, J. Geophys. Res.-Biogeo., 113, G00B01, doi:10.1029/2007JG000644, 2008.

Bousquet, P., Peylin, P., Ciais, P., Le Quéré, C., Friedlingstein, P., and Tans, P. P.: Regional changes in carbon dioxide fluxes of land and oceans since 1980, Science, 290, 1342-1347, 2000.

Brooks, R. H. and Corey, A. T.: Properties of porous media affecting fluid flow, J. Irrig. Drain. E.-ASCE, 92, 61-88, 1966.

Bruno, R. D., da Rocha, H. R., de Freitas, H. C., Goulden, M. L., and Miller, S. D.: Soil moisture dynamics in an eastern Amazonian tropical forest, Hydrol. Process., 20, 2477-2489, 2006.

Clapp, R. B. and Hornberger, G. M.: Empirical equations for some soil hydraulic properties, Water Resour. Res., 14, 601-604, 1978.

Cox, P.: Description of the TRIFFID dynamic global vegetation model, metoffice.gov.uk, available at: http://www.metoffice.gov. uk/media/pdf/9/h/HCTN_24.pdf, 2001.

Cox, P. M., Pearson, D., Booth, B. B., Friedlingstein, P., Huntingford, C., Jones, C. D., and Luke, C. M.: Sensitivity of tropical carbon to climate change constrained by carbon dioxide variability, Nature, 494, 341-344, 2013.

Da Rocha, H. R., Goulden, M. L., Miller, S. D., Menton, M. C., Pinto, L. D. V. O., de Freitas, H. C., and e Silva Figueira, A. M.: Seasonlity of water and heat fluxes over a tropical forest in eastern Amazonia, Ecol. Appl., 14, 22-32, 2004.

Da Rocha, H. R., Manzi, A. O., Cabral, O. M., Miller, S. D., Goulden, M. L., Saleska, S. R., Coupe, R.-N., Wofsy, S. C., Borma, L. S., Artaxo, P., Vourlitis, G., Nogueira, J. S., Cardoso, F. L., Nobre, A. D., Kruijt, B., Freitas, H. C., von
Randow, C., Aguiar, R. G., and Maia, J. F.: Patterns of water and heat flux across a biome gradient from tropical forest to savanna in Brazil, J. Geophys. Res.-Biogeo., 114, G00B12, doi:10.1029/2007JG000640, 2009.

Davidson, E. A., Verchot, L. V., Cattanio, J. H., Ackerman, I. L., and Carvalho, J. E. M.: Effects of soil water content on soil respiration in forests and cattle pastures of eastern Amazonia, Biogeochemistry, 48, 53-69, 2000.

de Carvalho Conceição Telles, de Camargo, P. B., Martinelli, L. A., Trumbore, S. E., da Costa, E. S., Santos, J., Higuchi, N., and Oliveira, R. C.: Influence of soil texture on carbon dynamics and storage potential in tropical forest soils of Amazonia, Global Biogeochem. Cy., 17, doi:10.1029/2002GB001953, 2003.

De Gonçalves, L. G. G., Borak, J. S., Costa, M. H., Saleska, S. R., Baker, I., Restrepo-Coupe, N., Muza, M. N., Poulter, B., Verbeeck, H., Fisher, J. B., Arain, M. A., Arkin, P., Cestaro, B. P., Christoffersen, B., Galbraith, D., Guan, X., van den Hurk, B. J. j. m., Ichii, K., Imbuzeiro, H. M. A., Jain, A. K., Levine, N., Lu, C., Miguez-Macho, G., Roberti, D. R., Sahoo, A., Sakaguchi, K., Schaefer, K., Shi, M., Shuttleworth, W. J., Tian, H., Yang, Z.L., and Zeng, X.: Overview of the Large-Scale BiosphereAtmosphere Experiment in Amazonia Data Model Intercomparison Project (LBA-DMIP), Agr. Forest Meteorol., 182, 111-127, 2013.

DeLucia, E. H., Drake, J. E., Thomas, R. B., and GonzalezMeler, M.: Forest carbon use efficiency: is respiration a constant fraction of gross primary production?, Glob. Change Biol., 13, 1157-1167, 2007.

De Weirdt, M., Verbeeck, H., Maignan, F., Peylin, P., Poulter, B., Bonal, D., Ciais, P., and Steppe, K.: Seasonal leaf dynamics for tropical evergreen forests in a process-based global ecosystem model, Geosci. Model Dev., 5, 1091-1108, doi:10.5194/gmd-51091-2012, 2012.

Dirmeyer, P. A.: A history and review of the Global Soil Wetness Project (GSWP), J. Hydrometeorol., 12, 729-749, 2011.

Doughty, C. and Goulden, M.: Seasonal patterns of tropical forest leaf area index and $\mathrm{CO}_{2}$ exchange, J. Geophys. Res., 113, G00B06, doi:10.1029/2007JG000590, 2008.

Dufresne, J.-L., Foujols, M.-A., Denvil, S., Caubel, A., Marti, O., Aumont, O., Balkanski, Y., Bekki, S., Bellenger, H., Benshila, R., Bony, S., Bopp, L., Braconnot, P., Brockmann, P., Cadule, P., Cheruy, F., Codron, F., Cozic, A., Cugnet, D., de Noblet, N., Duvel, J.-P., Ethé, C., Fairhead, L., Fichefet, T., Flavoni, S., Friedlingstein, P., Grandpeix, J.-Y., Guez, L., Guilyardi, E., Hauglustaine, D., Hourdin, F., Idelkadi, A., Ghattas, J., Joussaume, S., Kageyama, M., Krinner, G., Labetoulle, S., Lahellec, A., Lefebvre, M.-P., Lefevre, F., Levy, C., Li, Z. X., Lloyd, J., Lott, F., Madec, G., Mancip, M., Marchand, M., Masson, S., Meurdesoif, Y., Mignot, J., Musat, I., Parouty, S., Polcher, J., Rio, C., Schulz, M., Swingedouw, D., Szopa, S., Talandier, C., Terray, P., Viovy, N., and Vuichard, N.: Climate change projections using the IPSL-CM5 Earth System Model: from cmIP3 to CMIP5, Clim. Dynam., 40, 2123-2165, 2013.

El-Masri, B., Barman, R., Meiyappan, P., Song, Y., Liang, M., and Jain, A. K.: Carbon dynamics in the Amazonian Basin: integration of eddy covariance and ecophysiological data with a land surface model, Agr. Forest Meteorol., 182, 156-167, 2013.

Fu, R., Yin, L., Li, W., Arias, P. A., Dickinson, R. E., Huang, L., Chakraborty, S., Fernandes, K., Liebmann, B., Fisher, R., and 
Myneni, R. B.: Increased dry-season length over southern Amazonia in recent decades and its implication for future climate projection, P. Natl. Acad. Sci. USA, 110, 18110-18115, doi:10.1073/pnas.1302584110, 2013.

Gatti, L. V., Gloor, M., Miller, J. B., Doughty, C. E., Malhi, Y., Domingues, L. G., Basso, L. S., Martinewski, A., Correia, C. S. C., Borges, V. F., Freitas, S., Braz, R., Anderson, L. O., Rocha, H., Grace, J., Phillips, O. L., and Lloyd, J.: Drought sensitivity of Amazonian carbon balance revealed by atmospheric measurements, Nature, 506, 76-80, 2014.

Goulden, M. L., Miller, S. D., da Rocha, H. R., Menton, M. C., de Freitas, H. C., e Silva Figueira, A. M., and de Sousa, C. A. D.: Diel and seasonal patterns of tropical forest $\mathrm{CO}_{2}$ exchange, Ecol. Appl., 14, 42-54, 2004.

Griffin, D. M.: Water potential as a selective factor in the microbial ecology of soils, in: Water Potential Relations in Soil Microbiology, edited by: Parr, J., Gardner, W., and Elliott, L., Soil Sci. Soc. Am., 141-151, 1981.

Heinsch, F. A., Reeves, M., Votava, P., Kang, S., Milesi, C., Zhao, M., Glassy, J., Jolly, W. M., Loehman, R., Bowker, C. F., Kimball, J. S., Nemani, R. R., and Running, S. W.: User's Guide: GPP and NPP (MOD17A2/A3) Products, NASA MODIS Land Algorithm, version 2.0, 1-57, 2003.

Hirsch, A. I., Little, W. S., Houghton, R. A., Scott, N. A., and White, J. D.: The net carbon flux due to deforestation and forest re-growth in the Brazilian Amazon: analysis using a processbased model, Glob. Change Biol., 10, 908-924, 2004.

Jobbágy, E. G. and Jackson, R. B.: The vertical distribution of soil organic carbon and its relation to climate and vegetation, Ecol. Appl., 10, 423-436, 2000.

Keller, M., Palace, M., and Hurtt, G.: Biomass estimation in the Tapajos National Forest, Brazil: examination of sampling and allometric uncertainties - new directions in tropical forest research, For. Ecol. Manage., 154, 371-382, 2001.

Keller, M., Alencar, A., Asner, G. P., Braswell, B., Bustamante, M., Davidson, E., Feldpausch, T., Fernandes, E., Goulden, M., Kabat, P., Kruijt, B., Luizão, F., Miller, S., Markewitz, D., Nobre, A. D., Nobre, C. A., Priante Filho, N., da Rocha, H., Silva Dias, P., von Randow, C., and Vourlitis, G. L.: Ecology research in the Large-Scale Biosphere-Atmosphere Experiment in Amazonia: early results, Ecol. Appl., 14, 3-16, 2004.

Keller, M., Varner, R., Dias, J. D., Silva, H., Crill, P., de Oliveira, R. C., and Asner, G. P.: Soil-atmosphere exchange of nitrous oxide, nitric oxide, methane, and carbon dioxide in logged and undisturbed forest in the Tapajos National Forest, Brazil, Earth Interact., 9, 1-28, doi:10.1175/ei125.1, 2005.

Kim, Y., Knox, R. G., Longo, M., Medvigy, D., Hutyra, L. R., Pyle, E. H., Wofsy, S. C., Bras, R. L., and Moorcroft, P. R.: Seasonal carbon dynamics and water fluxes in an Amazon rainforest, Glob. Change Biol., 18, 1322-1334, 2012.

Kirschbaum, M. U. F.: The temperature dependence of soil organic matter decomposition, and the effect of global warming on soil organic C storage, Soil Biol. Biochem., 27, 753-760, 1995.

Lee, J.-E., Oliveira, R. S., Dawson, T. E., and Fung, I.: Root functioning modifies seasonal climate, P. Natl. Acad. Sci. USA, 102, 17576-17581, 2005.

Malhi, Y., Wood, D., Baker, T. R., Wright, J., Phillips, O. L., Cochrane, T., Meir, P., Chave, J., Almeida, S., Arroyo, L., Higuchi, N., Killeen, T. J., Laurance, S. G., Laurance, W. F.,
Lewis, S. L., Monteagudo, A., Neill, D. A., Vargas, P. N., Pitman, N. C. A., Quesada, C. A., Salomao, R., Silva, J. N. M., Lezama, A. T., Terborgh, J., Martinez, R. V., and Vinceti, B.: The regional variation of aboveground live biomass in old-growth Amazonian forests, Glob. Change Biol., 12, 1107-1138, 2006.

Malhi, Y., Aragão, L. E. O. C., Metcalfe, D. B., Paiva, R., Quesada, C. A., Almeida, S., Anderson, L., Brando, P., Chambers, J. Q., Da Costa, A. C. L., Hutyra, L. R., Oliveira, P., PATIÑO, S., Pyle, E. H., Robertson, A. L., and Teixeira, L. M.: Comprehensive assessment of carbon productivity, allocation and storage in three Amazonian forests, Glob. Change Biol., 15, 1255-1274, 2009a.

Malhi, Y., Aragão, L. E. O. C., Galbraith, D., Huntingford, C., Fisher, R., Zelazowski, P., Sitch, S., McSweeney, C., and Meir, P.: Exploring the likelihood and mechanism of a climatechange-induced dieback of the Amazon rainforest, P. Natl. Acad. Sci. USA, 106, 20610-20615, 2009b.

Melton, J. R. and Arora, V. K.: Sub-grid scale representation of vegetation in global land surface schemes: implications for estimation of the terrestrial carbon sink, Biogeosciences, 11, 10211036, doi:10.5194/bg-11-1021-2014, 2014.

Miller, S., Goulden, M., and da Rocha, H. R.: LBA-ECO CD04 Meteorological and Flux Data, km 83 Tower Site, Tapajos National Forest, Data Set, available at: http://daac.ornl.gov, Oak Ridge National Laboratory Distributed Active Archive Center, Oak Ridge, Tennessee, USA, doi:10.3334/ORNLDAAC/946, 2009.

Miller, S. D., Goulden, M. L., Menton, M. C., da Rocha, H. R., de Freitas, H. C., Figueira, A. M. e S., and Dias de Sousa, C. A.: Biometric and micrometeorological measurements of tropical forest carbon balance, Ecol. Appl., 14, 114-126, 2004.

Miller, S. D., Goulden, M. L., and da Rocha, H. R.: The effect of canopy gaps on subcanopy ventilation and scalar fluxes in a tropical forest, Agr. Forest Meteorol., 142, 25-34, 2007.

Miller, S. D., Goulden, M. L., Hutyra, L. R., Keller, M., Saleska, S. R., Wofsy, S. C., Figueira, A. M. S., da Rocha, H. R., and de Camargo, P. B.: Reduced impact logging minimally alters tropical rainforest carbon and energy exchange, P. Natl. Acad. Sci. USA, 108, 19431-19435, 2011.

Morton, D. C., Nagol, J., Carabajal, C. C., Rosette, J., Palace, M., Cook, B. D., Vermote, E. F., Harding, D. J., and North, P. R. J.: Amazon forests maintain consistent canopy structure and greenness during the dry season, Nature, 506, 221-224, doi:10.1038/nature13006, 2014.

Nepstad, D. C., de Carvalho, C. R., Davidson, E. A., Jipp, P. H., Lefebvre, P. A., Negreiros, G. H., da Silva, E. D., Stone, T. A., Trumbore, S. E., and Vieira, S.: The role of deep roots in the hydrological and carbon cycles of Amazonian forests and pastures, Nature, 372, 666-669, 1994.

Oliveira, R. S., Dawson, T. E., Burgess, S. S. O., and Nepstad, D. C.: Hydraulic redistribution in three Amazonian trees, Oecologia, 145, 354-363, 2005.

Orchard, V. A. and Cook, F.: Relationship between soil respiration and soil moisture, Soil Biol. Biogeochem., 15, 447-453, 1983.

Poulter, B., Heyder, U., and Cramer, W.: Modeling the sensitivity of the seasonal cycle of GPP to dynamic LAI and soil depths in tropical rainforests, Ecosystems, 12, 517-533, 2009.

Restrepo-Coupe, N., da Rocha, H. R., Hutyra, L. R., da Araujo, A. C., Borma, L. S., Christoffersen, B., Cabral, O. M. 
r., de Camargo, P. B., Cardoso, F. L., da Costa, A. C. L., Fitzjarrald, D. R., Goulden, M. L., Kruijt, B., Maia, J. M. f., Malhi, Y. S., Manzi, A. O., Miller, S. D., Nobre, A. D., von Randow, C., Sá, L. D. A., Sakai, R. K., Tota, J., Wofsy, S. C., Zanchi, F. B., and Saleska, S. R.: What drives the seasonality of photosynthesis across the Amazon basin?, A cross-site analysis of eddy flux tower measurements from the Brasil flux network, Agr. Forest Meteorol., 182, 128-144, 2013.

Rohr, T., Manzoni, S., Feng, X., Menezes, R. S. C., and Porporato, A.: Effect of rainfall seasonality on carbon storage in tropical dry ecosystems, J. Geophys. Res.-Biogeo., 118, 1-12, doi:10.1002/jgrg.20091, 2013.

Rowland, L., Hill, T. C., Stahl, C., Siebicke, L., Burban, B., Zaragoza-Castells, J., Ponton, S., Bonal, D., Meir, P., and Williams, M.: Evidence for strong seasonality in the carbon storage and carbon use efficiency of an Amazonian forest, Glob. Change Biol., 20, 979-991, 2014.

Saleska, S. R., Miller, S. D., Matross, D. M., Goulden, M. L., Wofsy, S. C., da Rocha, H. R., de Camargo, P. B., Crill, P., Daube, B. C., de Freitas, H. C., Hutyra, L., Keller, M., Kirchhoff, V., Menton, M., Munger, J. W., Pyle, E. H., Rice, A. H., and Silva, H.: Carbon in Amazon forests: unexpected seasonal fluxes and disturbance-induced losses, Science, 302, 1554-1557, 2003.

Silver, W. L., Neff, J., McGroddy, M., Veldkamp, E., Keller, M., and Cosme, R.: Effects of soil texture on belowground carbon and nutrient storage in a lowland Amazonian Forest ecosystem, Ecosystems, 3, 193-209, 2000.

Sombroek, W.: Spatial and temporal patterns of Amazon rainfall, Ambio, 30, 388-396, 2001.

Tang, J. and Zhuang, Q.: Equifinality in parameterization of process-based biogeochemistry models: A significant uncertainty source to the estimation of regional carbon dynamics, J. Geophys. Res.-Biogeosci., 113, doi:10.1029/2008JG000757, 2008.

Telles, E. C. C., Camargo, P. B., Martinelli, L. A., Trumbore, S. E., Costa, E. S., Santos, J., Higuchi, N., and Oliveira Jr., R. C.: Influence of soil texture on carbon dynamics and storage potential in tropical forest soils of Amazonia, Global Biogeochem. Cy., 17, 1040, doi:10.1029/2002GB001953, 2003.
Van Genuchten, M. T.: A closed form equation for predicting the hydraulic conductivity of unsaturated soils, Soil Sci. Soc. Am. J., 44, 892-898, 1980.

Verseghy, D.: CLASS - the Canadian Land Surface Scheme (Version 3.6), Technical Documentation, Tech. rep., Science and Technology Branch, Environment Canada, 2012.

Verseghy, D. L.: CLASS - a Canadian land surface scheme for GCMs, I. Soil model, Int. J. Climatol., 11, 111-133, 1991.

Von Randow, C., Zeri, M., Restrepo-Coupe, N., Muza, M. N., de Gonçalves, L. G. G., Costa, M. H., Araujo, A. C., Manzi, A. O., da Rocha, H. R., Saleska, S. R., Arain, M. A., Baker, I. T., Cestaro, B. P., Christoffersen, B., Ciais, P., Fisher, J. B., Galbraith, D., Guan, X., van den Hurk, B., Ichii, K., Imbuzeiro, H., Jain, A., Levine, N., Miguez-Macho, G., Poulter, B., Roberti, D. R., Sahoo, A., Schaefer, K., Shi, M., Tian, H., Verbeeck, H., and Yang, Z.-L.: Inter-annual variability of carbon and water fluxes in Amazonian forest, Cerrado and pasture sites, as simulated by terrestrial biosphere models, Agr. Forest Meteorol., 182, 145-155, 2013.

Zeri, M., Sá, L. D. A., Manzi, A. O., Araújo, A. C., Aguiar, R. G., von Randow, C., Sampaio, G., Cardoso, F. L., and Nobre, C. A.: Variability of carbon and water fluxes following climate extremes over a tropical forest in southwestern Amazonia, PLoS One, 9, e88130, doi:10.1371/journal.pone.0088130, 2014.

Zhang, D., Hui, D., Luo, Y., and Zhou, G.: Rates of litter decomposition in terrestrial ecosystems: global patterns and controlling factors, J. Plant Ecol., 1, 85-93, 2008.

Zhao, M., Heinsch, F. A., Nemani, R. R., and Running, S. W.: Improvements of the MODIS terrestrial gross and net primary production global data set, Remote Sens. Environ., 95, 164-176, 2005.

Zobler, L.: A World Soil File for Global Climate Modelling, NASA Technical Memorandum 87802, NASA Goddard Institute for Space Studies, New York, USA, 1986. 